\title{
Asymmetric Synthetic Strategies of $(R)-(-)$-Baclofen: An Antispastic Drug
}

\author{
Perla Ramesh* (D) \\ Devatha Suman \\ Koti Siva Nagi Reddy \\ CSIR-Indian Institute of Chemical Technology, Tarnaka, \\ Hyderabad-500007, Telangana, India \\ chemryams@gmail.com \\ Dedicated to Dr. Nitin W. Fadnavis, Natural Products \\ Chemistry Division, IICT, Hyderabad on the occasion of his \\ 63rd birthday
}

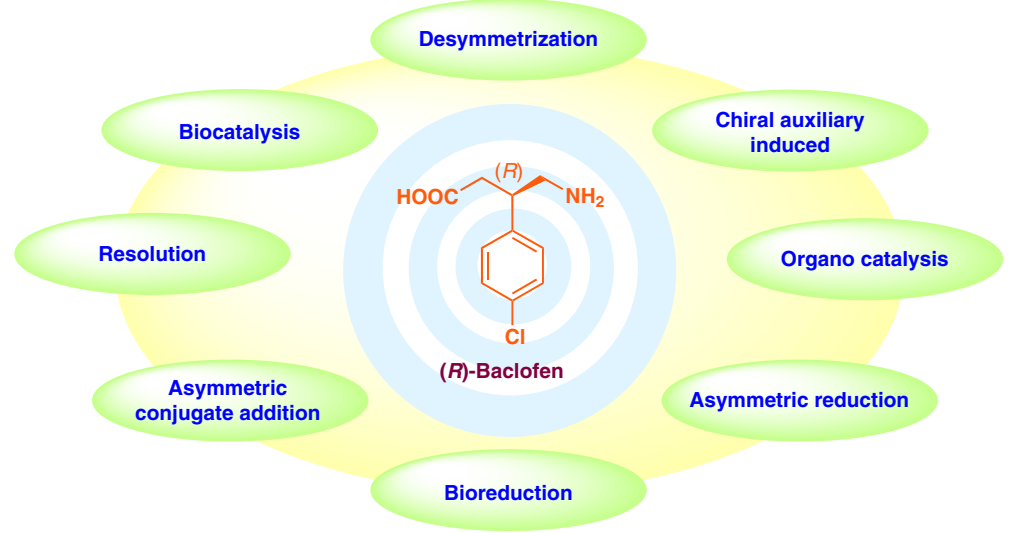

Received: 11.07.2017

Accepted after revision: 26.09.2017

Published online: 20.10 .2017

DOI: 10.1055/s-0036-1590938; Art ID: ss-2017-m0419-sr

Abstract Baclofen is an antispastic drug used as a muscle relaxant in the treatment of the paroxysmal pain of trigeminal neuralgia, spasticity of the spinal cord and cerebral origin. Baclofen resides biological activity exclusively in its $(R)-(-)$-enantiomer. In this review, various asymmetric synthetic strategies for $(R)-(-)$-baclofen are described.

1 Introduction

2 Resolution Synthetic Approaches

2.1 Chemical Resolution

2.2 Biocatalytic Resolution

3 Asymmetric Desymmetrization

3.1 Catalytic Enantioselective Desymmetrization

3.2 Enzymatic Desymmetrization

4 Chiral Auxiliary Induced Asymmetric Synthesis

4.1 Asymmetric Michael Addition

4.2 Asymmetric Aldol Addition

4.3 Asymmetric Nucleophilic Substitution

5 Asymmetric Reduction

5.1 Catalytic Asymmetric Hydrogenation

5.2 Bioreduction

6 Catalytic Asymmetric Conjugate Addition

7 Conclusion

Key words asymmetric synthesis, total synthesis, amino acids, chiral resolution, baclofen, synthetic methods, biocatalysis

\section{Introduction}

Baclofen [ $\gamma$-amino- $\beta$-(4-chlorophenyl)butyric acid, 1, Figure 1] was first designed as a drug for treating epilepsy by Heinrich Keberle in $1962 .{ }^{1}$ The effect of baclofen on epilepsy was disappointing, but it was found that spasticity was decreased in certain people. In 1992, it was approved and marketed under the trade name of Lioresal ${ }^{\circledR}$ for the

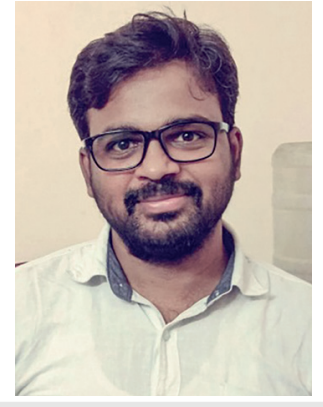

Dr. Perla Ramesh was born in a small village Obulapoor, Siddipet District, Telangana, India. He graduated from Osmania University, Hyderabad in 2006. After obtaining his M.Sc. in 2008 from Kakatiya University, he joined the group of Dr. Nitin W. Fadnavis at the Indian Institute of Chemical Technology, Hyderabad, India, where he carried out his doctoral studies in the field of synthetic organic chemistry and biotransformation. His research interests include the total synthesis of bioactive natural products and pharmaceutical drugs and development of new reactions.

treatment of spasticity. The molecular weight of baclofen is $213.66 \mathrm{~g} / \mathrm{mol}$; it is a white odorless crystalline powder and slightly soluble in water.

Baclofen (1), a strongly lipophilic $\gamma$-aminobutyric acid (GABA) analogue, plays an important role as an inhibitory neurotransmitter in the central nervous system. ${ }^{2}$ It helps to reduce the excitatory effect of active compounds such as benzodiazepine, barbiturates, etc. ${ }^{3}$ A deficiency of GABA is associated with diseases that exhibit neuromuscular dysease and epilepsy. ${ }^{4}$ Baclofen is widely used as a muscle relaxant in the treatment of the paroxysmal pain of trigeminal neuralgia ${ }^{5}$ as well as spasticity of spinal cord and cerebral origin. ${ }^{6}$ Pharmacological studies suggest that the biological activity of baclofen resides exclusively in the (-)functions, including Parkinson's disease, Huntington's dis- 
enantiomer only, ${ }^{7}$ therefore, access to (-)-baclofen in an enantiomerically pure form is of great importance. The absolute configuration of (-)-baclofen was assigned as $R$ configuration on the basis of X-ray crystallography analysis. ${ }^{8}$

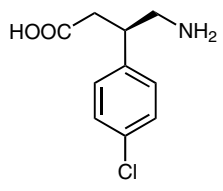

(R)-1

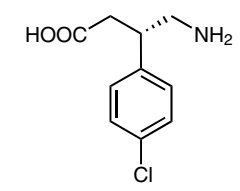

(S)-1
Figure 1 Structure of baclofen (1)

\section{Resolution Synthetic Approaches}

\subsection{Chemical Resolution}

In 1997, Caira and co-workers reported the large-scale production of $(R)$-baclofen $[(R)-\mathbf{1}]$ using a chemical resolution method (Scheme 1). ${ }^{9}$ This method involved direct resolution of racemic 3-(4-chlorophenyl)glutaramic acid (rac-2) by diastereomeric salt formation with $(S)-(-)-\alpha$-phenylethylamine. The reaction of rac-2 with $(S)$ - $\alpha$-phenylethylamine in methanol readily gave diastereomeric $(S)-\alpha-$ phenylethylamine salts, which were separated by crystallization. The structures of the diastereomeric salts were established by X-ray diffraction analysis. The optically pure salt was treated with aqueous $\mathrm{NaOH}$ then neutralized with dilute $\mathrm{HCl}$ to afford $(R)-\mathbf{2}$, which was converted into selective GABA receptor agonist $(R)$-baclofen $[(R)-\mathbf{1}]$ by Hofmann reaction in $57 \%$ yield with $99.8 \%$ ee.
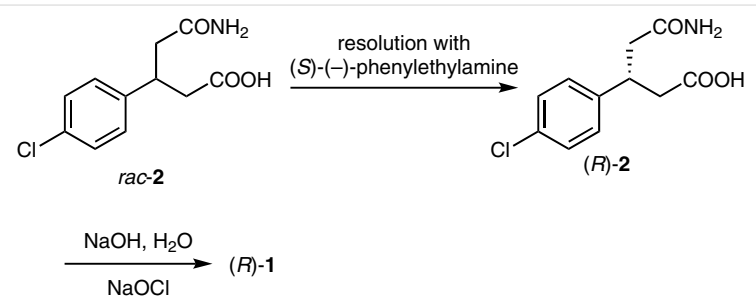

Scheme 1 Chemical resolution by (S)-(-)- $\alpha$-phenylethylamine

Muñoz-Torrero, Sánchez, and Camps ${ }^{10}$ reported the resolution of racemic $\gamma$-nitro acid rac-4 using $(R)-N$-phenylpantolactam (5) as a chiral auxiliary (Scheme 2); rac-4 was obtained from $\mathbf{3}$ via a three-step sequence (esterification, Michael addition with nitromethane, and ester hydrolysis). The esterification of rac-4 with $(R)-N$-phenylpantolactam (5) gave a 1:1 mixture of two diastereomers, which was subjected to column chromatography to obtain $\mathbf{6}$ in $22 \%$ yield and >98:2 dr. On the other hand, compound $\mathbf{6}$ was also synthesized in 17\% yield with 96:4 dr (after column chromatography) by the Michael addition of nitromethane to chiral auxiliary compound 7. Hydrolysis of compound $\mathbf{6}$ in the presence of LiOH furnished $(R)-4$ in $84 \%$ yield with $>99 \%$ ee with the recovery of $(R)-N$-phenylpantolactam $(5)$ in $91 \%$ yield. Reduction of the nitro group in $(R)-\mathbf{4}$ catalyzed by Raney nickel and then acid hydrolysis completed the synthetic sequence to give $(R)$-baclofen $[(R)-1]$ in $91 \%$ yield. Similarly, reduction followed by acid hydrolysis of compound 6 provided $(R)$-baclofen $[(R)-1]$ via the formation of chiral intermediate $(R)$-8. ( $S)$-Baclofen was also synthesized by using $(S)-\mathbf{5}$ as a chiral auxiliary.
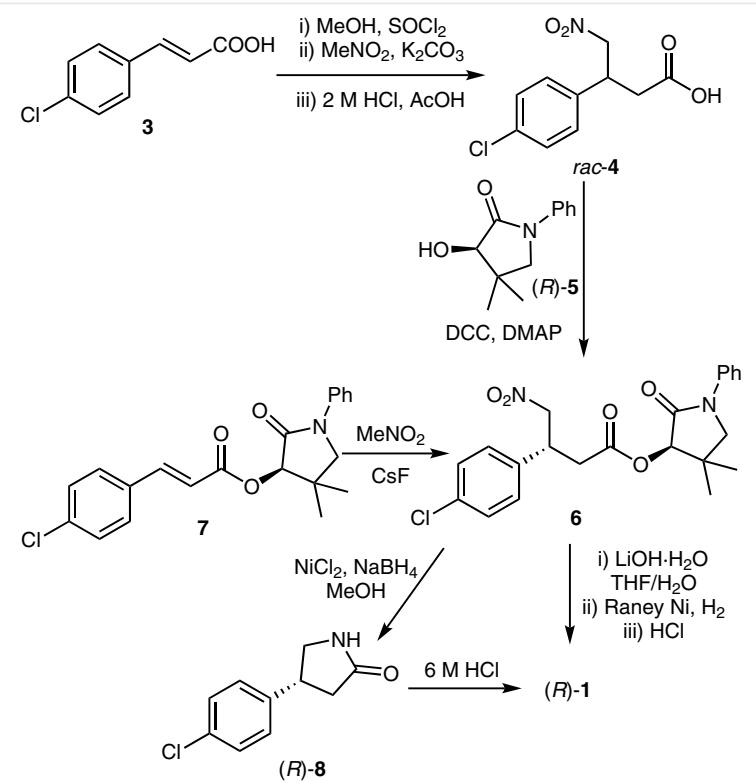

Scheme 2 Resolution using ( $R$ )-N-phenylpantolactam

In 2015, Linzaga-Elizalde and co-workers ${ }^{11}$ described the synthesis of optically pure pyrrolidinone intermediate $(R)-\mathbf{8}$ by using chemical resolution method as a key step (Scheme 3). Condensation of aldehyde $\mathbf{1 0}$ with dimethyl malonate (9) in the presence of piperidine base afforded the diester 11, which on Michael addition with nitromethane yielded nitro diester 12. Catalytic hydrogenation of 12 in the presence of Raney nickel yielded 13 which on hydrolysis of the ester group followed by decarboxylation provided the desired rac-8. The racemic compound rac-8 was coupled with optically pure $\mathbf{1 4}$ to give a mixture of diastereomers, which was separated by using column chromatography. Removal of the chiral naproxen auxiliary from the diastereomerically pure imide $\mathbf{1 5}$, provided optically pure $(R)-8$ in $79 \%$ yield, which on acid hydrolysis yielded $(R)$-baclofen $[(R)-\mathbf{1}]$. 


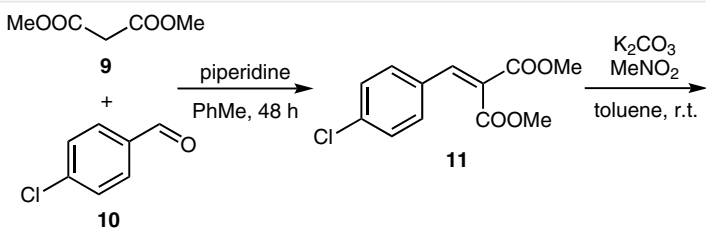<smiles>COC(=O)C(C(=O)OC)C(C[N+](=O)[O-])c1ccc(Cl)cc1</smiles>
12 13<smiles>COc1ccc2cc(C(C)C(=O)O)ccc2c1</smiles><smiles>COc1ccc2cc([C@H](C)C(=O)N3C[C@H](c4ccc(Cl)cc4)CC3=O)ccc2c1</smiles>

Scheme 3 Resolution using (S)-naproxen

\subsection{Biocatalytic Resolution}

Biocatalysts are widely used in organic synthesis and the pharmaceutical industry as environmentally friendly catalysts for the synthesis of optically pure chiral intermediates under mild reaction conditions. ${ }^{12}$

Microbial hydrolysis of 2-arylpent-4-enenitriles $\mathbf{1 6}$ was investigated by Wang and Zhao using Rhodococcus sp. AJ270 nitrile hydratase amidase as a biocatalyst (Scheme 4). ${ }^{13}$ Thus the reactions were performed under milder and environmentally friendly conditions. Excellent enantioselectivity was observed with 2-(4-chlorophenyl)pent-4-enenitrile (16, $0.5 \mathrm{mmol})$, in the presence of Rhodococcus sp. AJ270, in

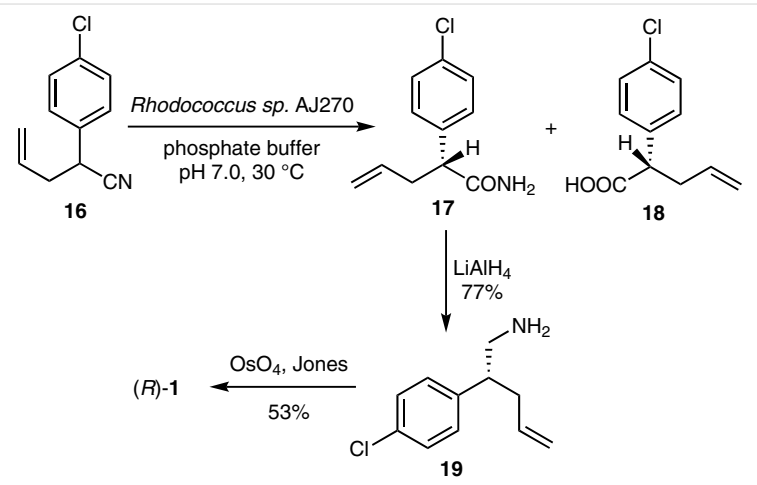

Scheme 4 Rhodococcus sp. AJ270 catalyzed resolution
$0.1 \mathrm{M}$ phosphate buffer solution $(\mathrm{pH} 7)$ at $30{ }^{\circ} \mathrm{C}$. After a reaction time of 6 days, amide $(R)-\mathbf{1 7}$ and acid $(S)$-18 were obtained with $99 \%$ ee ( $44 \%$ yield) and $99 \%$ ee (50\% yield), respectively. A further increase of substrate concentration to $1 \mathrm{mmol}$ actually decreased the enantioselectivity and prolonged the reaction time. The chiral amide $\mathbf{1 7}$ was reduced with $\mathrm{LiAlH}_{4}$ to afford the corresponding amine 19, which was then oxidized to $(R)$-baclofen $[(R)-\mathbf{1}]$ using $\mathrm{OsO}_{4}$ and Jones' reagent.

The enzymatic resolution of racemic methyl 3-(4-chlorophenyl)-4-nitrobutanoate (21) by ester hydrolysis, in 0.1 $\mathrm{M}$ phosphate buffer solution at $\mathrm{pH} 7.4$, using $\alpha$-chymotrypsin was described by Felluga and co-workers (Scheme 5). ${ }^{14}$ When the reaction was stopped at $53 \%$ conversion, the unreacted ester $(R)-\mathbf{2 1}$ was isolated with $99.9 \%$ ee (42\% yield) and $(S)$-acid with $96 \%$ ee in $43 \%$ yield (enantioselectivity $>200)$. (R)-Baclofen $[(R)-1]$ was obtained by hydrolysis of the optically pure $\gamma$-nitro ester $(R)$-21 followed by the reduction of the nitro group on Raney nickel.
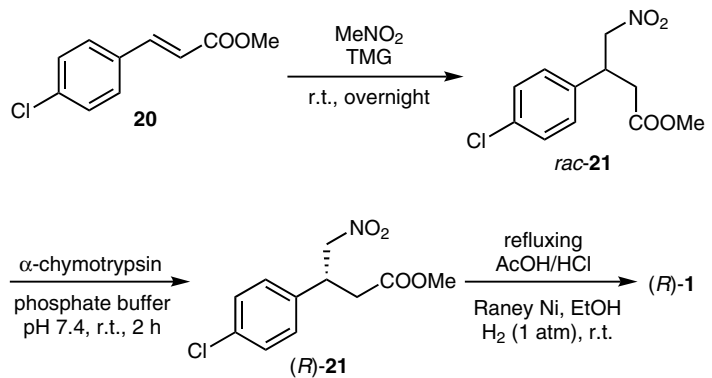

Scheme $5 \alpha$-Chymotrypsin-catalyzed resolution

The hydrolysis of racemic butyl 4-amino-3-(4-chlorophenyl)butanoate ( $r a c-22 a)$, catalyzed by the same protease ( $\alpha$-chymotrypsin) was also described by Veinberg and co-workers (Scheme 6). ${ }^{15}$ The reaction was carried out in phosphate buffer ( $\mathrm{pH} \mathrm{6-7)}$ or phosphate buffer/dioxane ratio (10:1) or phosphate buffer/acetone ratio (10:2). Good enantioselectivity was reported for this reaction with the formation of pyrrolidinone $(S)-\mathbf{8}$ (98\% ee), and the recovery of unreacted ester $(R)-\mathbf{2 2 a}$ in $97 \%$ ee from racemic $\mathbf{2 2 a}$. Acid hydrolysis of the ester group in $(R)$-22a gave $(R)$-baclofen [(R)-1].

\section{Asymmetric Desymmetrization}

Enantioselective desymmetrization of prochiral and meso compounds is the most important strategy to produce an optically pure single enantiomer in 100\% theoretical yield and $100 \%$ optical purity. For this reason, asymmetric desymmetrization constitutes the most important alternative to kinetic resolution methods for the synthesis of optically pure compounds. ${ }^{16}$ 


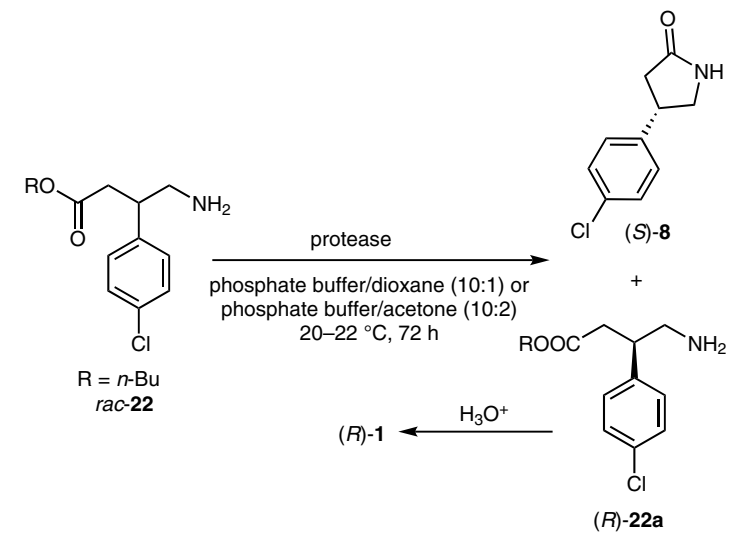

Scheme 6 Protease-catalyzed resolution

\subsection{Catalytic Enantioselective Desymmetrization}

In 2000-2001, Deng and co-workers developed an asymmetric methanolysis of cyclic anhydrides using modified cinchona alkaloids as chiral Lewis base catalysts. ${ }^{17}$ Tak-

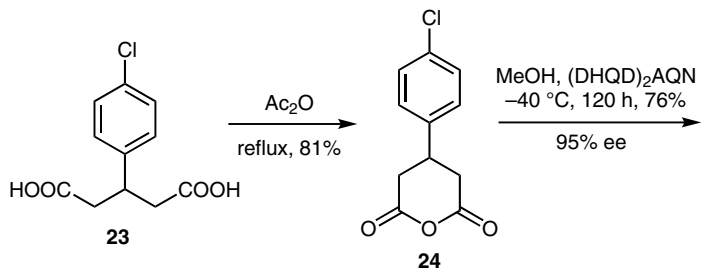

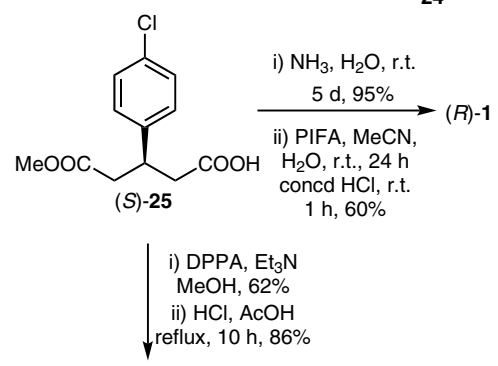

(S)-1

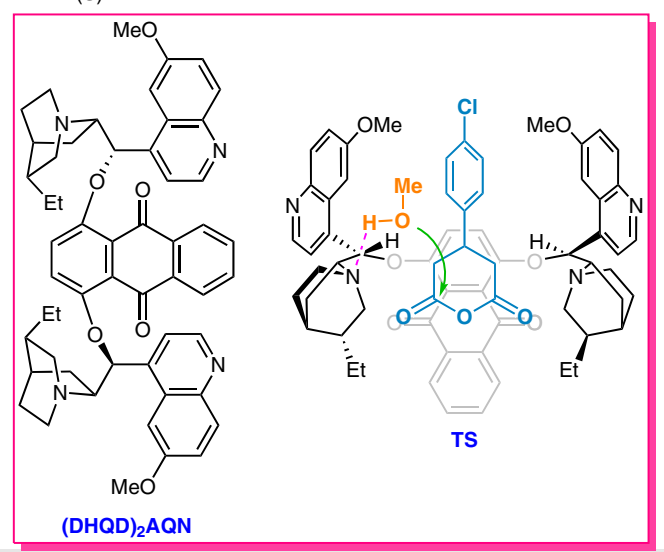

Scheme 7 Desymmetrization of a meso-cyclic anhydride with a modified cinchona alkaloid ing advantage of this method, the asymmetric synthesis of $(R)$-baclofen $[(R)-1]$ using (DHQD) ${ }_{2} \mathrm{AQN}$-catalyzed enantioselective meso-cyclic anhydride 24 desymmetrization as a key step was accomplished by Zhang and co-workers in 2009 (Scheme 7). ${ }^{18}$ The meso-cyclic anhydride 24 was prepared from 23 by treatment with acetic anhydride. The asymmetric methanolysis of meso-cyclic anhydride 24 using (DHQD) ${ }_{2} \mathrm{AQN}$ catalyst $(10 \mathrm{~mol} \%)$ provided hemiester $(S)-\mathbf{2 5}$ in $\mathbf{7 6 \%}$ yield with $95 \%$ ee. It is proposed that the anhydride fits into a U-shaped conformation of the (DHQD) ${ }_{2} \mathrm{AQN}$ catalyst ${ }^{19}$ as shown in the transition state. The chiral amine of the catalyst activates the methanol nucleophile via hydrogen bonding. Then the activated methanol nucleophile attacks the nearest carbonyl group of the anhydride to produce the desired product $\mathbf{2 5}$ with absolute $S$ configuration. Ammonolysis of monoester (S)-25 with aqueous ammonia yielded amide $(R)-\mathbf{2}$, which was then treated with [bis(trifluoroacetoxy)iodo]benzene (PIFA) and hydrochloric acid to provide $(R)$-baclofen $[(R)-\mathbf{1}]$ in $60 \%$ yield. Similarly, $(S)$-baclofen was also prepared from $(S)-25$ by Curtius rearrangement followed by acid hydrolysis.

In 2016, Chen and co-workers ${ }^{20}$ also described deracemization of meso-cyclic anhydrides using newly synthesized chloramphenicol-base-derived thiourea organocatalysts. The best result for deracemization of meso-cyclic anhydride $\mathbf{2 4}$ was achieved giving $(R)-\mathbf{2 5}$ with $80 \%$ ee and $98 \%$ yield using $10 \mathrm{~mol} \%$ of $\mathbf{A}$ as the catalyst. The enantiopurity of $(R)$-25 was increased to $95 \%$ ee after recrystallization ( $n$ hexane/EtOAc, 20:1). The tertiary amino group of the catalyst activates the alcohol by hydrogen bonding, while the thiourea group activates the anhydride by double hydrogen bonding as shown in the transition state. Quantum chemi-
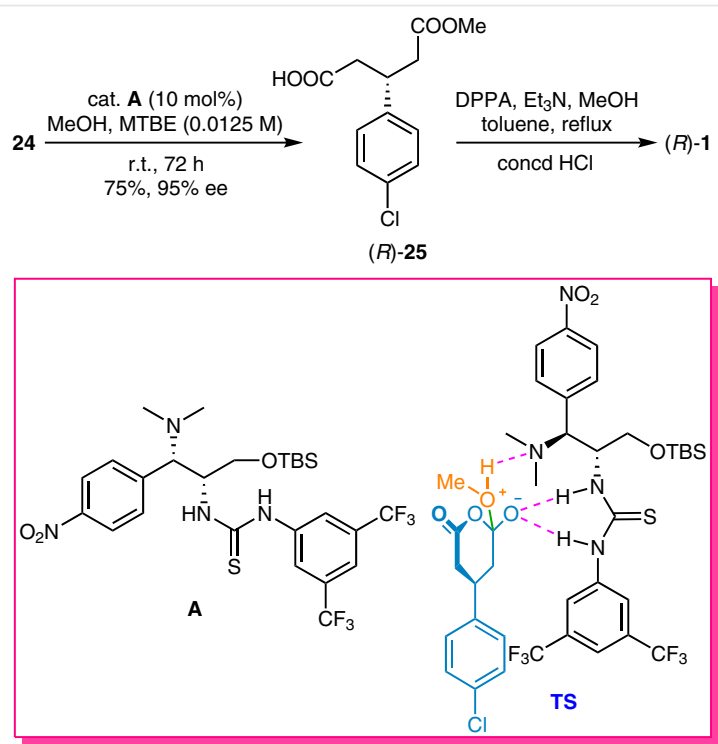

Scheme 8 Enantioselective desymmetrization using a chloramphenicol-base-derived thiourea organocatalyst 
cal calculations provided the theoretical explanation for the enantioselectivity of the catalyst and stability of the transition states. ${ }^{21}$ The hemiester $(R)-\mathbf{2 5}$ was then converted into $(R)$-baclofen $[(R)-1]$ using Curtius rearrangement followed by acid hydrolysis in $80 \%$ yield over two steps (Scheme 8 ).

\subsection{Enzymatic Desymmetrization}

Chenevert and Desjardins ${ }^{22}$ have employed two different enantioselective enzymatic desymmetrization approaches for the synthesis $(R)$-baclofen: 1 . hydrolysis of a meso-ester using $\alpha$-chymotrypsin, and 2 . acylation of the meso-alcohol by a transesterification reaction using PPL. The $\alpha$-chymotrypsin-catalyzed ester hydrolysis of symmetrical dimethyl 3-(4-chlorophenyl)pentanedioate (26) afforded the desymmetrized monoester $(R)-\mathbf{2 5}$ in $85 \%$ yield with $98 \%$ ee. Curtius rearrangement of $(R)-\mathbf{2 5}$ followed by acid hydrolysis provided the target molecule $(R)-\mathbf{1}$ through the formation of isocyanate $\mathbf{2 7}$ (Scheme 9).

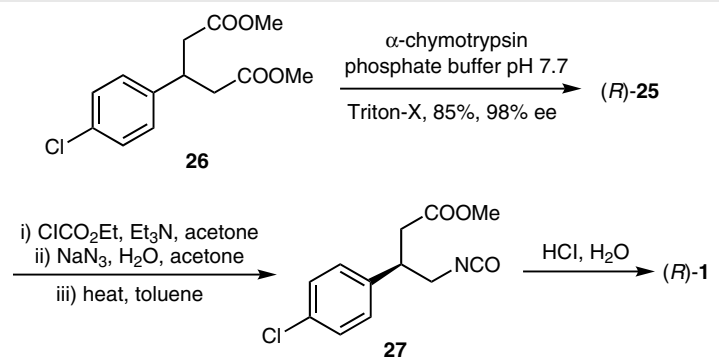

Scheme $9 \alpha$-Chymotrypsin-catalyzed desymmetrization

They also desymmetrized 2-(4-chlorophenyl)propane1,3-diol (28) through PPL-catalyzed transesterification (Scheme 10). The transesterification process led to the monoacetate of $(S)$-configuration 29, which was isolated in $93 \%$ yield with $96 \%$ ee. Mesylation of the free alcohol in hemiester 29 using $\mathrm{MsCl}$ followed by nucleophilic substitution with cyanide provided $\mathbf{3 0}$. Removal of the acetyl group from 30, 0 -mesylation, followed by displacement of the mesylate group with azide furnished the cyano azide $\mathbf{3 1}$. Finally, azide group reduction followed by acid hydrolysis of the cyanide group yielded $(R)$-baclofen $[(R)-\mathbf{1}]$.

Furstoss and co-workers ${ }^{23}$ reported a seven-step synthesis of $(R)$-baclofen using a microbiologically mediated Baeyer-Villiger oxidation as a key step (Scheme 11). The prochiral intermediate $\mathbf{3} 3$ was prepared from commercially available 4-chlorostyrene (32) in two steps. ${ }^{24}$ The stereoselective oxidation of prochiral ketone $\mathbf{3 3}$ in the presence of the fungus Cunninghamella echinulata NRLL 3655 provided $(R)$-chlorobenzyl lactone $\mathbf{3 4}$ in 30\% yield with 99\% ee. Lac-

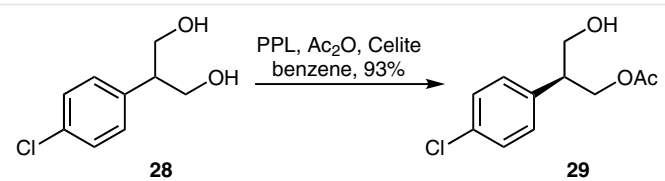

28

29
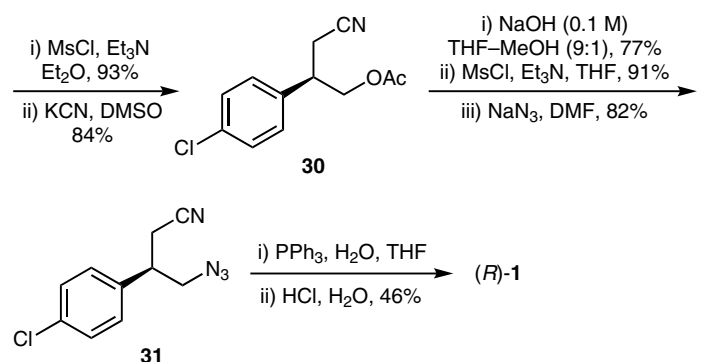

Scheme 10 PPL-catalyzed desymmetrization

tone opening of 34 with $\mathrm{Me}_{3} \mathrm{SiI}$ and EtOH followed by reaction with $\mathrm{NaN}_{3}$ gave azido ester 35. Hydrolysis of the ester group in $\mathbf{3 5}$ followed by reduction of the azide group provided the target molecule $(R)-\mathbf{1}$.
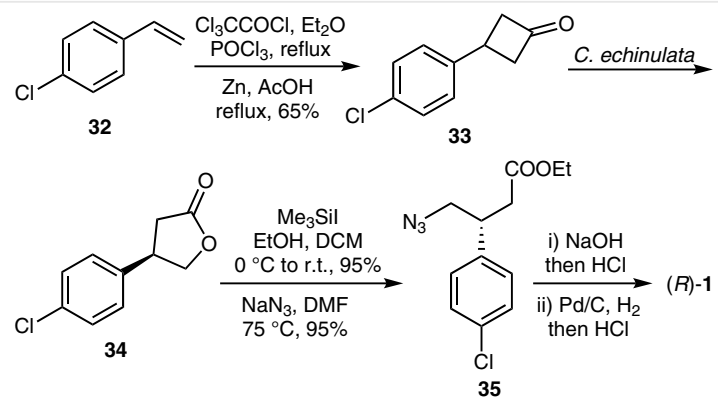

Scheme 11 Cunninghamella echinulata NRLL 3655 catalyzed desymmetrization

Wang and co-workers ${ }^{25}$ reported the microbial desymmetrization of 3-arylglutaronitriles. The enantioselective hydrolysis of prochiral intermediate $\mathbf{3 6}$ catalyzed by Rhodococcus sp. AJ270 in aqueous buffer at $30{ }^{\circ} \mathrm{C}$ provided $(S)-37$ in $37 \%$ yield with low enantiomeric excess (26\%). However, in the presence of acetone as an additive the enantiomeric excess increased to 63\%. In 2014, the desymmetrization of the 3-substituted glutaronitriles was attempted in the presence of several nitrilases from diverse sources by Wu, Zhu, and co-workers. ${ }^{26}$ Among them, AtNIT3 nitrilase produced $(R)-37$, whereas BjNIT6402 and HsNIT nitrilases generated the opposite enantiomer $(S)$-37 with high conversion and ee values. Finally, HsNIT nitrilase afforded the monoacid $(S)-37$ in $80 \%$ yield with $99 \%$ ee. Curtius rearrangement of $(R)$-37 and subsequent acid hydrolysis yielded $(R)$-baclofen $[(R)-1]$ (Scheme 12). 


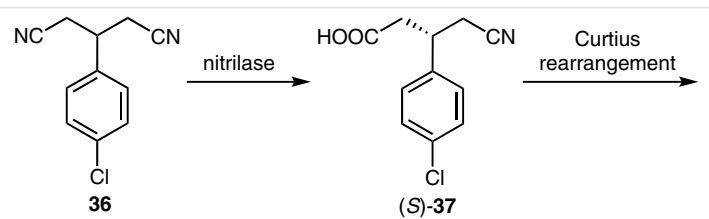<smiles>COC(=O)C[C@H](CC#N)c1ccc(Cl)cc1</smiles>

Scheme 12 Nitrilase-catalyzed desymmetrization

\section{Chiral Auxiliary Induced Asymmetric Syn- thesis}

\subsection{Asymmetric Michael Addition}

Several synthetic routes to $(R)$-baclofen using chiral auxiliary induced diastereoselective conjugate addition have been reported. One contribution, a chiral auxiliary induced enantioselective synthesis approach by the Licandro group, ${ }^{27 a}$ utilized the diastereoselective Michael addition of Fischer-type amino carbene $\mathbf{3 9}$ to (E)-4-chloro- $\beta$-nitrostyrene (40) to give $\mathbf{4 1}$ as a mixture of diastereomers in $90 \%$ yield and $76 \%$ de (Scheme 13 ).

The Licandro group ${ }^{27 b}$ proposed that the presence of an electronic interaction between the negatively charged $\mathrm{Cr}(\mathrm{CO})_{5}{ }^{-}$group and the chlorine group of the nitrostyrene on the $R e$ face of the proposed transition state leads to the formation of the desired $S, S, R$-diastereomer as the major product. The optically pure $S, S, R$-isomer $\mathbf{4 1}$ was then isolated in $77 \%$ yield using silica gel column chromatography. Compound $\mathbf{4 1}$ was completely transformed into amide $\mathbf{4 2}$ using the oxidizing agent CAN; compound $\mathbf{4 2}$ on reduction followed by hydrolysis afforded $(R)$-baclofen $[(R)-\mathbf{1}]$.

Kuo and Wong ${ }^{28}$ reported that the tetramethylguanidine (TMG)-catalyzed diastereoselective conjugate addition of nitromethane to chiral $\alpha, \beta$-unsaturated oxazolidinone $\mathbf{4 3}$ provided 44 with 93:7 $\mathrm{dr}$ (Scheme 14). The purity of compound 44 could be increased to $99 \%$ de (78\% yield) by crystallization from ethyl acetate. Removal of the chiral auxiliary group followed by reduction provided $(R)$-baclofen $[(R)$ 1] in $65 \%$ yield with $99 \%$ ee.

Oba, Nishiyama, and co-workers ${ }^{29}$ reported the synthesis of non-proteinogenic amino acids via Michael addition to an $\alpha, \beta$-unsaturated orthopyroglutamate derivative. Compound $\mathbf{4 6}$ was synthesized by Michael addition of Gilman reagent $\left(4-\mathrm{ClC}_{6} \mathrm{H}_{4}\right)_{2} \mathrm{CuMgBr}$ to unsaturated pyroglutamate
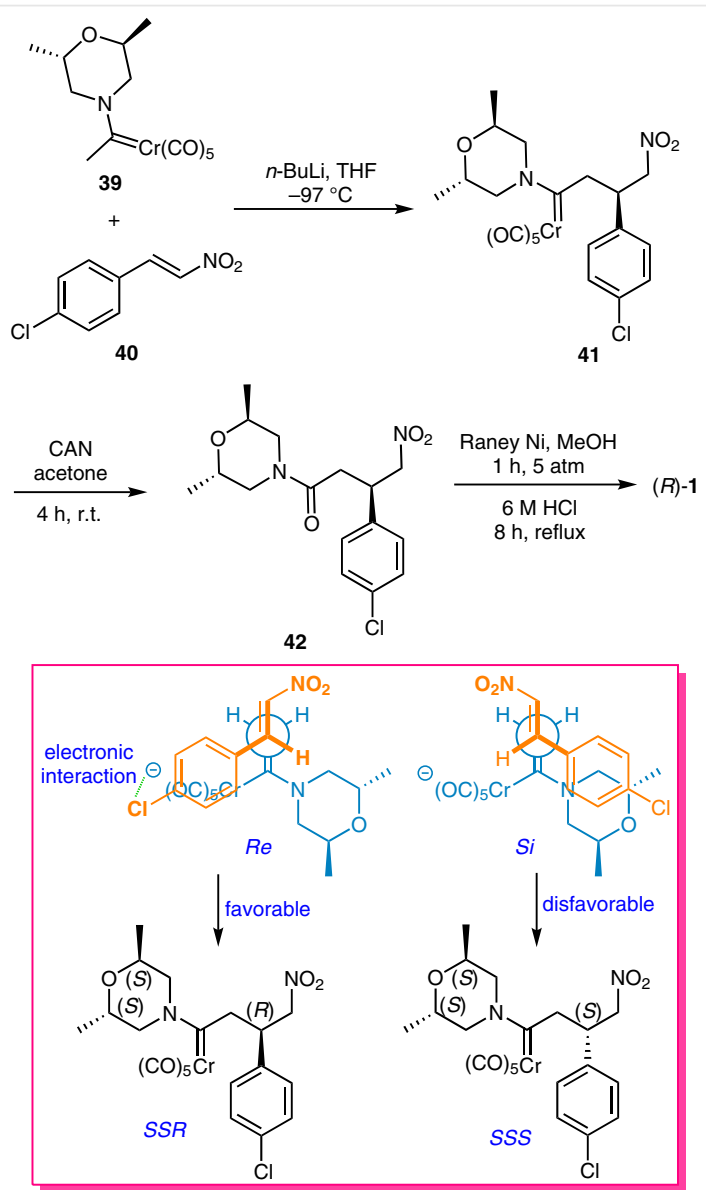

Scheme 13 Diastereoselective Michael addition of Fischer-type amino carbene

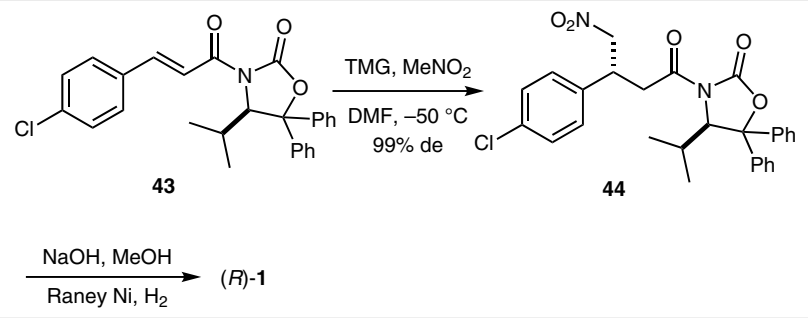

Scheme 14 TMG-catalyzed diastereoselective conjugate addition

derivative $\mathbf{4 5}$ in 68\% yield (Scheme 15). Methanolysis of the orthoester function followed by concomitant Boc group deprotection with $\mathrm{HCl}$ in methanol yielded $\mathbf{4 7}$ in $\mathbf{7 5 \%}$ yield. Benzyl protection of the lactam nitrogen followed by LiOHpromoted ester hydrolysis provided the desired pyroglutamic acid 48, which could be converted into $(R)$-baclofen $[(R)-\mathbf{1}]$ as described by Chang and co-workers. ${ }^{30,31}$ 

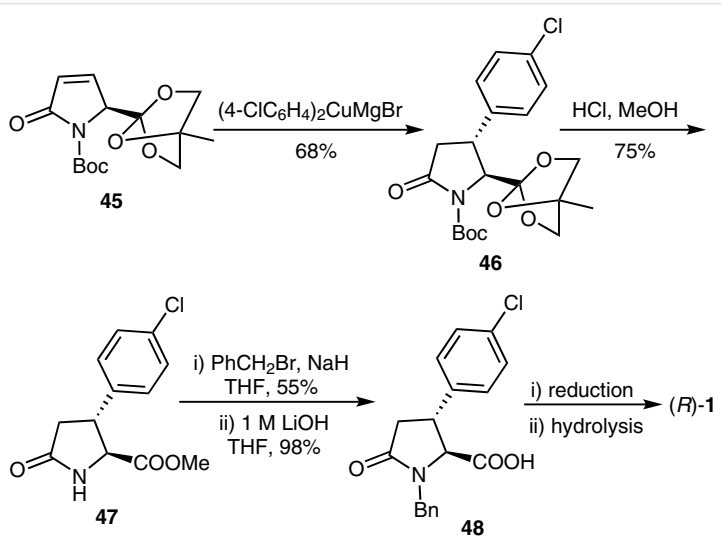

Scheme 15 Michael addition to unsaturated orthopyroglutamate

\subsection{Asymmetric Aldol Addition}

Nair and co-workers ${ }^{32}$ reported the synthesis of $(R)$-baclofen $[(R)-\mathbf{1}]$ using a diastereoselective aldol reaction (Scheme 16). Acetate aldol addition using the titanium enolate of (S)-1-(5-isopropyl-3-phenyl-2-thioxoimidazolidin1-yl)ethan-1-one (49) with 4-chlorobenzaldehyde (10) at $-78{ }^{\circ} \mathrm{C}$ in $\mathrm{CH}_{2} \mathrm{Cl}_{2}$ provided compound $\mathbf{5 0}$ in $69 \%$ yield with 98:2 dr. The titanium enolate was formed when $N$-acylated imidazolidine-2-thione 49 reacted with 2 equivalents of $\mathrm{TiCl}_{4}$ and 1 equivalent of DIPEA. The aldehyde approaches the titanium enolate from the sterically less hindered face (bottom face) to form a highly favored chelated transition state and provide the syn-acetate aldol adduct as the major diastereomer. The chiral auxiliary of aldol adduct $\mathbf{5 0}$ was removed by treatment with $\mathrm{K}_{2} \mathrm{CO}_{3}$ in EtOH to obtain compound 51. Bromination of $\mathbf{5 1}$ afforded the $\beta$-bromo ester $\mathbf{5 2}$, which was then converted by reaction with TMSCN/TBAF into the corresponding $\beta$-cyano ester 53a. Subsequent reduction followed by acid hydrolysis provided $(R)$-baclofen $[(R)-\mathbf{1}]$ with high enantiopurity.

\subsection{Asymmetric Nucleophilic Substitution}

Schoenfelder and co-workers ${ }^{33}$ reported the enantioselective synthesis of $(R)$-baclofen $[(R)-1]$ (Scheme 17). The chiral imide $\mathbf{5 4}$ was coupled with tert-butyl bromoacetate in an Evans asymmetric alkylation reaction to give the alkylated product 55 in $82 \%$ yield and 95:5 dr. Deprotonation of $\mathbf{5 4}$ by means of sodium hexamethyldisilazanide results in the $Z$-enolate transition state. Chelation of the auxiliary carbonyl group to the sodium restricts the confirmation so that the isopropyl group shields the top face of the enolate. Therefore, the tert-butyl bromoacetate electrophile approaches from the bottom face with high diastereoselectivity. ${ }^{34}$ Removal of the oxazolidinone chiral auxiliary from $\mathbf{5 5}$ under mild basic conditions followed by selective ester reduction in the presence of $\mathrm{BH}_{3}$. DMS yielded the desired lac-
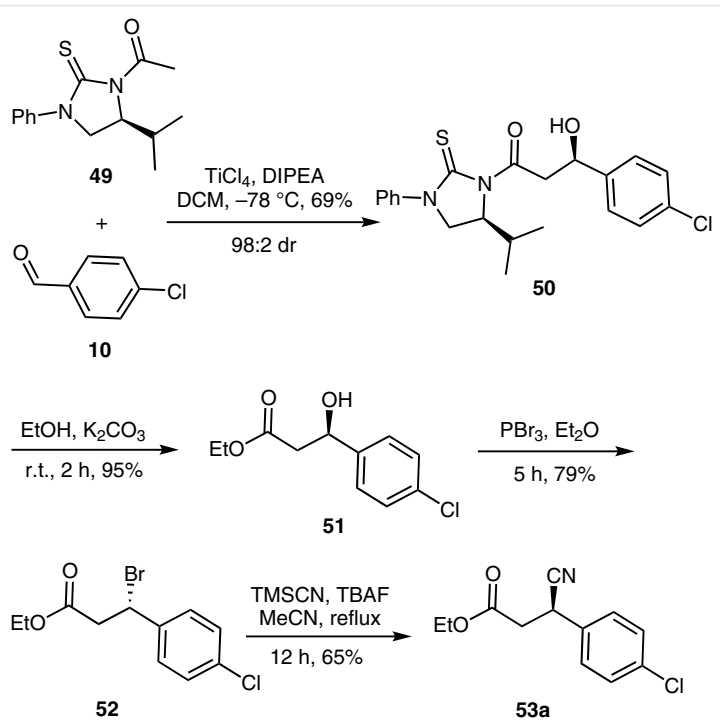

$$
\begin{aligned}
& \underset{\mathrm{NiCl}_{2} \cdot 6 \mathrm{H}_{2} \mathrm{O}}{\mathrm{NaBH}_{4}, \mathrm{MeOH}} \\
& \text { r.t., } 1 \mathrm{~h}, 86 \% \\
& \underset{\text { concd } \mathrm{HCl}}{\text { reflux, } 12 \mathrm{~h}} \\
& 80 \%
\end{aligned}(R)-1
$$

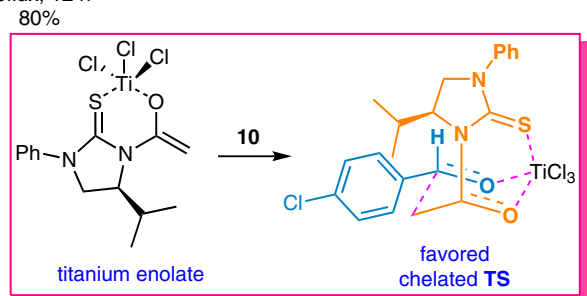

Scheme 16 Asymmetric aldol addition

tone product 34. The lactone $\mathbf{3 4}$ was transformed into the azide ester 35 using lactone opening with $\mathrm{HBr} / \mathrm{EtOH}$ followed by halogen displacement with $\mathrm{NaN}_{3}$. Finally, the reduction of azide group and acid hydrolysis yielded the target molecule through the formation of lactam $(R)-8$.

An efficient and short asymmetric synthesis of $(R)$-baclofen $[(R)-\mathbf{1}]$ has been described by Enders and Niemeier (Scheme 18). ${ }^{35}$ The $\alpha$-alkylation of $\mathbf{5 6}$ with methyl bromoacetate in the presence of the strong base lithium diisopropylamide (LDA) afforded $\mathbf{5 7}$ with $96 \%$ de (84\% yield). Deprotonation of SAMP-hydrazone $\mathbf{5 6}$ with strong base LDA produces an azaenolate with $E_{\mathrm{C}-\mathrm{C}}, Z_{\mathrm{C}-\mathrm{N}}$ geometry, and lithium cation chelated by the oxygen and nitrogen atoms as shown in the transition state. ${ }^{36}$ The steric repulsions between the pyrrolidine ring of the SAMP-hydrazone and the methyl bromoacetate hinder the attack of the methyl bromoacetate from the top face. Thus, the methyl bromoacetate attacks from the bottom face, where the steric repulsions do not exist. ${ }^{37}$ The aldehyde hydrazone $\mathbf{5 7}$ was converted into nitrile product $(R)$-53b by oxidation in the presence of magnesium monoperoxyphthalate hexahydrate (MMPP). At this stage, the reaction conditions for the selective reduction of 
<smiles>CC(C)[C@H]1COC(=O)[C@H](CC(=O)O[SnH3])N1C(=O)Cc1ccc(Cl)cc1</smiles>

54

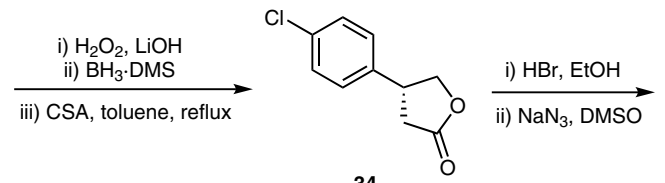<smiles>CCOC(=O)C[C@@H](CN)c1ccc(Cl)cc1</smiles>

$(R)-8$

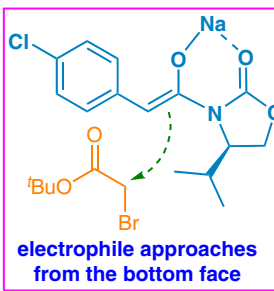

Scheme 17 Evans asymmetric alkylation

the nitrile group were optimized. The nitrile ester $(R)-\mathbf{5 3 b}$ was converted into $\gamma$-lactam $(R)-8$ using $\mathrm{NaBH}_{4}$ as the reducing agent in methanol at $-20^{\circ} \mathrm{C}$. Finally, the lactam $(R)$ 8 was hydrolyzed to give $(R)$-baclofen $[(R)-\mathbf{1}]$.
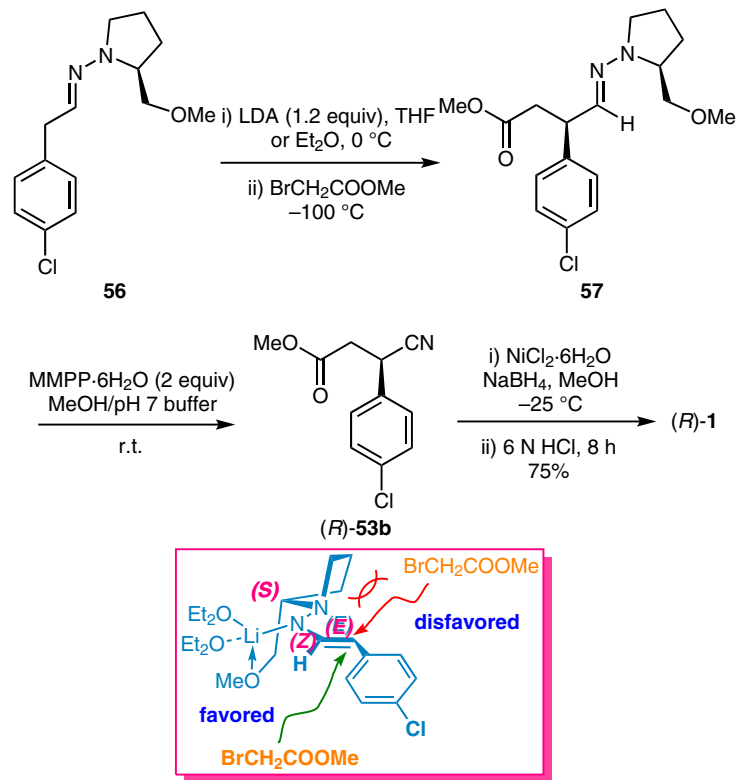

Scheme 18 Chiral auxiliary induced nucleophilic substitution

\section{Asymmetric Reduction}

\subsection{Catalytic Asymmetric Hydrogenation}

In 2003, Sudalai and co-workers ${ }^{38}$ reported a ruthenium-catalyzed asymmetric hydrogenation in the synthesis of $(R)$-baclofen $[(R)-\mathbf{1}]$. Compound $\mathbf{5 9}$ was prepared from 4chloroacetophenone (58) in 78\% yield (E/Z 70:30) using Znmediated Reformatsky reaction of ethyl bromoacetate followed by acid-catalyzed dehydration. The allylic bromination of 59 gave $\gamma$-bromo $\alpha, \beta$-unsaturated ester $\mathbf{6 0}$, which was subjected to $S_{N} 2$ reaction with $\mathrm{NaN}_{3}$ to obtain allylic azide 61. Enantioselective hydrogenation of prochiral compound $\mathbf{6 1}$ in the presence of $\mathrm{Ru}(\mathrm{II})-(S)$-BINAP in $\mathrm{MeOH}$ under $\mathrm{H}_{2}(\sim 13 \mathrm{~atm})$ at $50{ }^{\circ} \mathrm{C}$ afforded the chiral compound 35 in $68 \%$ yield with $68 \%$ ee. Compound $\mathbf{3 5}$ was converted into $(R)-\mathbf{1}$ with low ee (67\%) in two steps (Scheme 19).
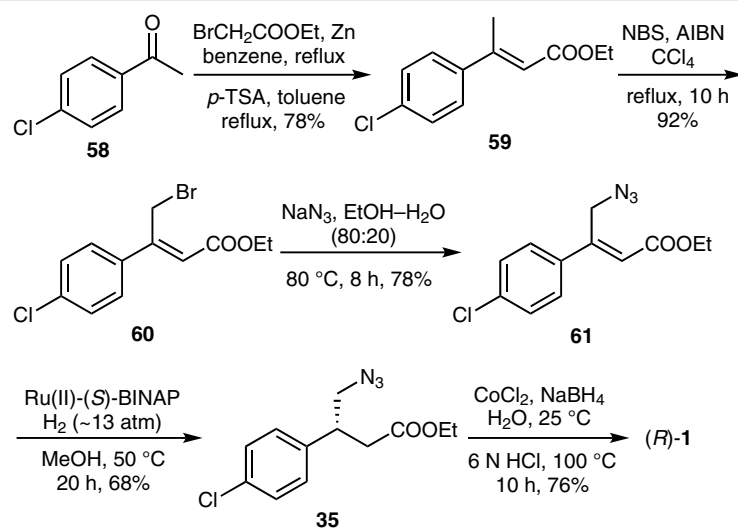

Scheme 19 Ru(II)-BINAP catalyzed asymmetric hydrogenation

On the other hand, the highly enantioselective hydrogenation of $\beta$-keto ester $\mathbf{6 2}$ was carried out in the presence of $\mathrm{Ru}(\mathrm{II})-(S)$-BINAP catalyst in $\mathrm{MeOH}$ under $\mathrm{H}_{2}$ (54 atm) to give $(R)$-hydroxy ester $\mathbf{5 1}$ in $95 \%$ yield with high enantioselectivity (96\% ee) (Scheme 20 ). The oxygen atoms in the $\beta$ keto ester coordinated to the ruthenium center of the $\mathrm{Ru}-(S)$-BINAP catalyst. Due to steric repulsions between the phenyl ring of (S)-BINAP and the 4-chlorophenyl group of the $\beta$-keto ester, the transition state on the right side is disfavored. The hydride ion is transferred from the ruthenium catalyst to the keto group through the favored transition state and provides the desired product $\mathbf{5 1}$ with absolute $R$ configuration. ${ }^{39}$ The chiral $\beta$-hydroxy ester $\mathbf{5 1}$ was converted into $(R)$-baclofen $[(R)-\mathbf{1}]$ in four steps by a similar method to that shown in Scheme 16.

Paraskar and Sudalai reported ${ }^{40}$ the synthesis of $(R)$-baclofen $[(R)-1]$ via enantioselective reduction of $\alpha, \beta$-unsaturated ester $\mathbf{6 1}$ using a cobalt-semicorrin complex. ${ }^{41} 4$-Chlorophenylboronic acid (63) and ethyl crotonate (64) are 


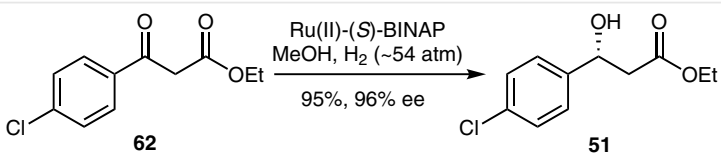

51
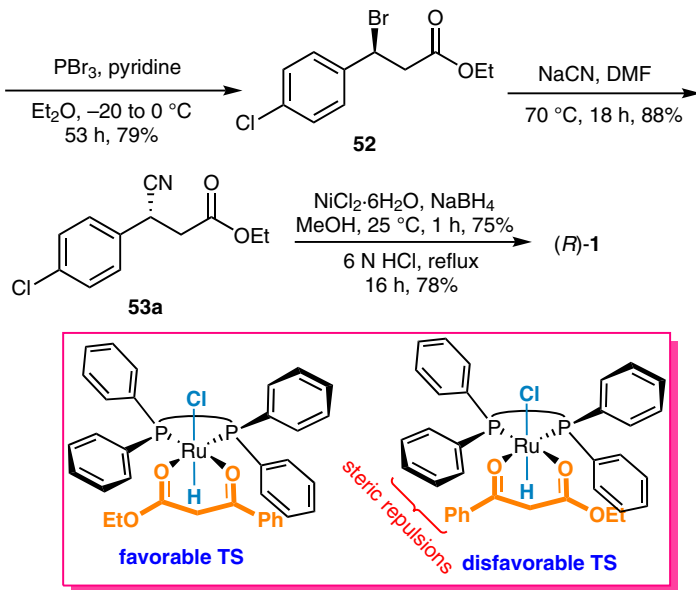

Scheme 20 Ruthenium(II)-BINAP catalyzed asymmetric hydrogenation

commercial products that were used as starting materials for the preparation of key precursor ethyl (Z)-4-azido-3-(4chlorophenyl)but-2-enoate (61) in a three-step sequence (Scheme 21). Arylation of ethyl crotonate with boronic acid 63 in the presence of palladium(II) acetate catalyst provided $\alpha, \beta$-unsaturated ester $\mathbf{5 9}$, which on allylic bromination followed by $\mathrm{S}_{\mathrm{N}} 2$ reaction with $\mathrm{NaN}_{3}$ yielded compound $\mathbf{6 1}$. A set of chiral ligands was screened for the reductive cyclization of azido-substituted unsaturated esters in the presence of $\mathrm{CoCl}_{2}$ and $\mathrm{NaBH}_{4}$. The chiral ligand $\mathbf{B}(1.1 \mathrm{~mol} \%)$

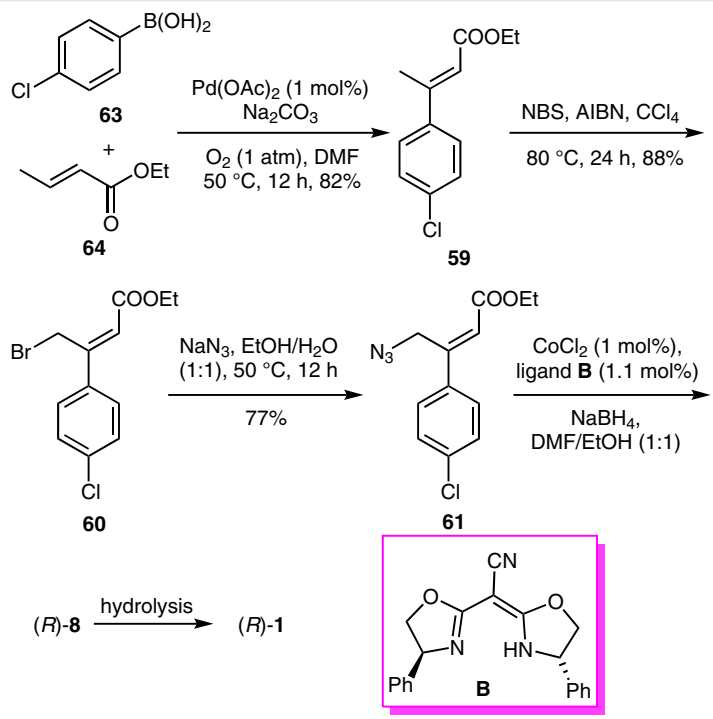

Scheme 21 Cobalt-catalyzed asymmetric reductive cyclization was found to be the best ligand, giving lactam $(R)-\mathbf{8}$ in $82 \%$ yield with $89 \%$ ee. Finally, acid hydrolysis of $(R)-\mathbf{8}$ afforded the hydrochloride salt of $(R)$-baclofen $[(R)-1]$ in $73 \%$ yield with $88 \%$ ee.

The asymmetric hydrogenation of $\gamma$-phthalimido- $\alpha, \beta$ unsaturated esters in the presence of a rhodium catalyst was reported by Zheng and co-workers in 2007.42 The prochiral substrate 65 was prepared from commercially available 4 -chloroacetophenone (58) via a three-step sequence: 1 . olefination of ketone $\mathbf{5 8}, 2$. allylic bromination, and 3. nucleophilic substitution with phthalimide. Optimization of the reaction conditions using $\left[\mathrm{Rh}(\mathrm{COD})_{2}\right] \mathrm{BF}_{4}$ as a catalyst revealed that $\left(S_{\mathrm{C}}, R_{\mathrm{Fc}}, R_{\mathrm{P}}\right)-\mathrm{C}$ and dichloromethane were the best ligand and solvent, respectively. Under the optimized reaction conditions, substrate $\mathbf{6 5}$ was transformed into the desired chiral compound $\mathbf{6 6}$ in 91\% yield with $99 \%$ ee after a single crystallization, which was then hydrolyzed with $6 \mathrm{~N} \mathrm{HCl}$ under reflux to give the $\mathrm{HCl}$ salt of $(R)$-baclofen $[(R)-\mathbf{1}]$ in quantitative yield (Scheme 22 ).
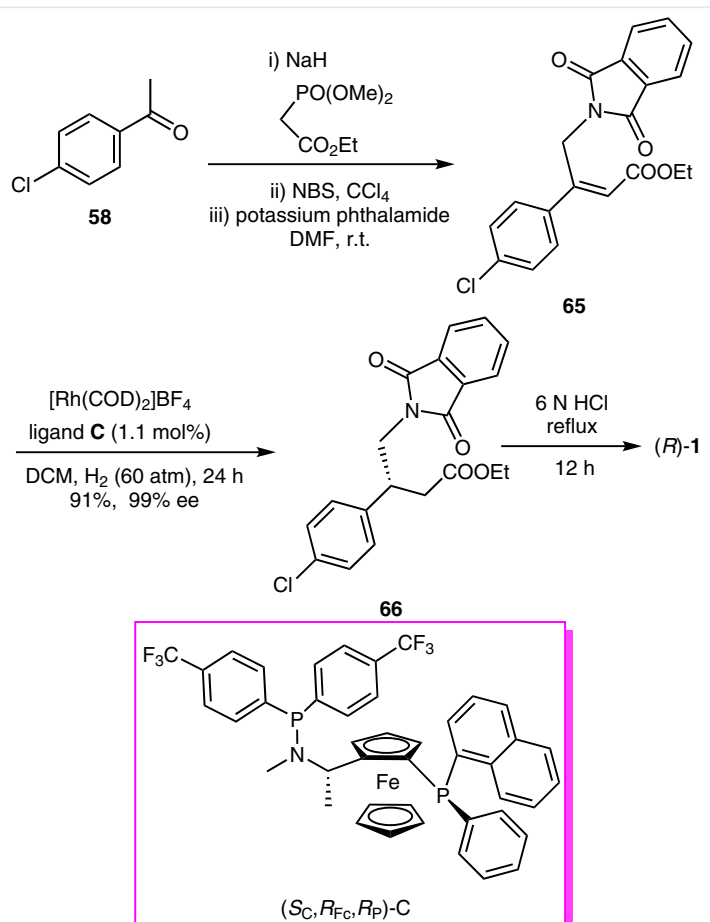

Scheme 22 Rhodium-catalyzed asymmetric hydrogenation

In 2008, Zheng and co-workers reported the asymmetric hydrogenation of $\mathbf{6 5}$ using $\mathrm{Cu}(\mathrm{OAC})_{2} \cdot \mathrm{H}_{2} \mathrm{O}$ as the catalyst and $(R)$ - or (S)-BINAP as the ligand (Scheme 23), ${ }^{43}$ together with PMHS as the hydride source and $t-\mathrm{BuOH}$ as an additive. Using this methodology the desired chiral compound 66 was obtained in 92\% yield with 94\% ee (98\% ee after recrystallization). 


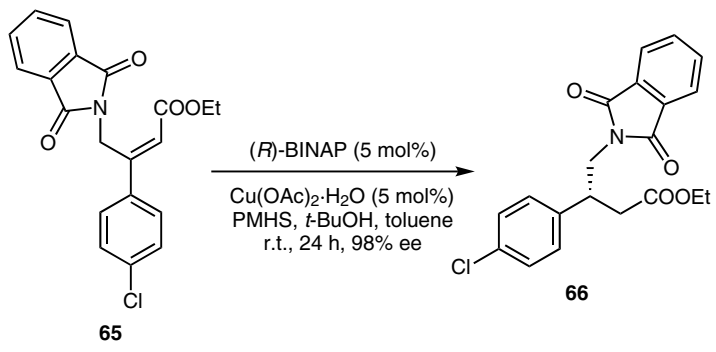

Scheme 23 Copper-catalyzed asymmetric 1,4-reduction

Mita, Higuchi, and Sato ${ }^{44}$ reported the carboxylation of allylic alcohols in the presence of a catalytic amount of $\mathrm{PdCl}_{2}$ under a $\mathrm{CO}_{2}$ atmosphere. Intermediate $\mathbf{6 8}$, prepared in $73 \%$ yield from 67 using optimal reaction conditions, was converted into butenolide 69, which on asymmetric reduction using Stryker's reagent in the presence of $(R)$-DTBMSEGPHOS afforded the key chiral intermediate $\mathbf{3 4}$ of $(R)$-baclofen $[(R)-1]$ in quantitative yield with $99 \%$ ee (Scheme 24 ).
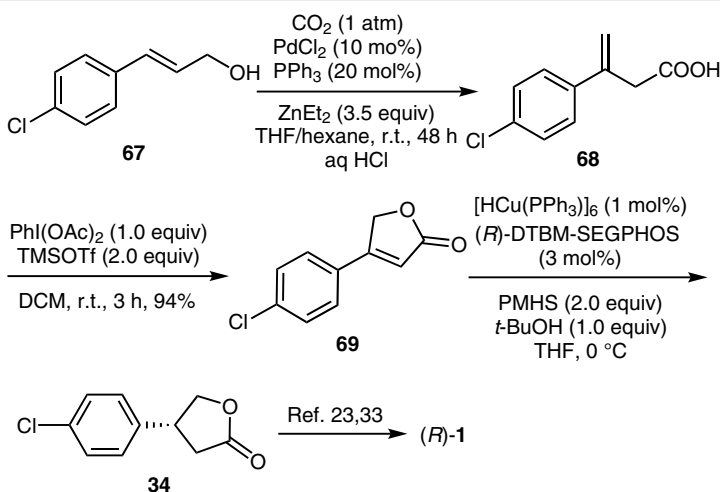

34

Scheme 24 Asymmetric reduction using Stryker's reagent

\subsection{Bioreduction}

In 2015, the tryptophan 116 mutant of Old Yellow Enzyme 1 (OYE1-W116L)-mediated bioreduction of (Z)-3aryl-3-cyanoacrylates was reported by Brenna and coworkers. ${ }^{45}$ The prochiral intermediate $\mathbf{7 1}$ was prepared by the condensation of arylacetonitrile $\mathbf{7 0}$ with glyoxylic acid in the presence of $\mathrm{K}_{2} \mathrm{CO}_{3}$ in methanol ${ }^{46}$ followed by esterification with MeI. The bioreduction of $\mathbf{7 1}$ in the presence of OYE1-W116L yielded $(R)-53 b$ with $90 \%$ ee. Finally, reduction of the nitrile group in the presence of $\mathrm{NiCl}_{2} \cdot 6 \mathrm{H}_{2} \mathrm{O}$ and $\mathrm{NaBH}_{4}$ followed by acid hydrolysis provided the target molecule $(R)-\mathbf{1}$ (Scheme 25).

On the other hand, Fryszkowska, Stephens, and coworkers described the bioreduction of potassium 3-(4-chlorophenyl)-3-cyanoacrylate (72) with reductase [Clostridium sporogenes (DSM 795) or Ruminococcus productus (DSM3507) or Acetobacterium woodii (DSM 1030)] from anaerobic bac-
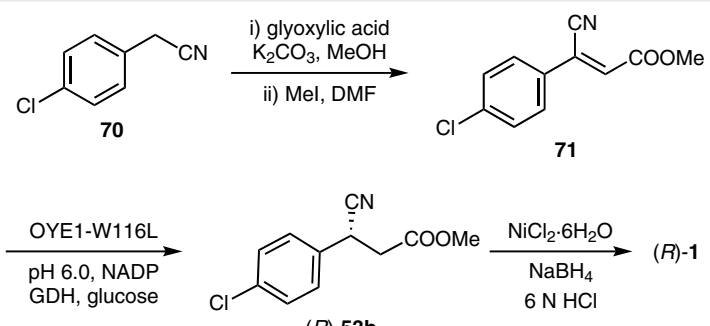

(R)-53b

Scheme 25 OYE1-W116L catalyzed bioreduction

teria to provide optically pure (S)-3-(4-chlorophenyl)-3-cyanopropanoic acid (73) in quantitative yields with high enantiomeric excess. ${ }^{47}$ After methylation, the ester $(S)-53 b$ was obtained in $83 \%$ yield with $95 \%$ ee from starting material 72. Enantiomerically pure compound $(S)$-53b ( $\geq 99 \%$ ee, $90 \%$ yield) was obtained after a single recrystallization, which was used in the synthesis of $(S)$-baclofen $[(S)-\mathbf{1}]$ (Scheme 26).
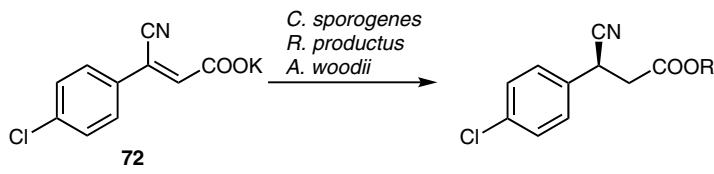

$$
\begin{array}{r}
\mathrm{Me}_{3} \mathrm{SiCH}_{2} \mathrm{~N}_{2} \\
83 \% \text { yield } \\
95 \% \text { ee } \mathrm{R}=\mathrm{H} ; \mathbf{7 3} \\
\begin{array}{r}
(99 \% \text { ee, } 90 \% \text { yield }) \\
\text { after one crystallization }
\end{array}
\end{array}
$$

Scheme 26 Biocatalytic reduction

\section{Catalytic Asymmetric Conjugate Addition}

Wang and co-workers ${ }^{48}$ and Liang, Ye, and co-workers ${ }^{49 a}$ independently published the organocatalytic asymmetric conjugate addition of nitromethane to $\alpha, \beta$-unsaturated aldehydes using (R)- or (S)-2-[diphenyl(trimethylsiloxy)methyl]pyrrolidine as the catalyst (Scheme 27). Wang and co-workers reported that the highly enantioselective Michael addition of nitromethane to unsaturated aldehyde 74 in the presence of proline derivative $\mathbf{D}$ ( $20 \mathrm{~mol} \%$ ) as the catalyst and benzoic acid (20 mol\%) as an additive in ethanol at $0{ }^{\circ} \mathrm{C}$ provided the corresponding Michael adduct $\mathbf{7 5}$ in $73 \%$ yield with high $96 \%$ ee. The benzoic acid additive can effectively increase the rate of the reaction as well as the amount of product. ${ }^{49 \mathrm{~b}}$ Similarly, Liang, Ye, and co-workers in 2008 reported that when the reaction was carried out in the presence of $\mathbf{D}(10 \mathrm{~mol} \%)$ as the catalyst and lithium acetate $\left(10 \mathrm{~mol} \%\right.$ ) as an additive in $\mathrm{CH}_{2} \mathrm{Cl}_{2} / \mathrm{MeOH}(1: 9)$ at room temperature, product $\mathbf{7 5}$ was obtained in $62 \%$ yield with $91 \%$ ee. When lithium acetate was used as the additive, the nucleophilicity of deprotonated nitromethane increased and it also accelerated the formation of the iminium ion. The observed stereochemistry is explained through the formation of enamine transition state, which could be formed 
from the catalyst $\mathbf{D}$ with the unsaturated aldehyde $\mathbf{7 4}$. The nitromethane nucleophile approaches the planar iminium ion from the $R e$ face (above the plane) due to the steric hindrance of Ph and OTMS bulky groups at the chiral center of the pyrrolidine ring in catalyst $\mathbf{D}$ and leads the observed stereochemistry. ${ }^{49 \mathrm{c}}$ The enantiomerically pure aldehyde $\mathbf{7 5}$ was further oxidized to $\gamma$-nitro acid $(R)-\mathbf{4}$ by reaction with $\mathrm{NaClO}_{2}$. Finally, catalytic hydrogenolysis of the nitro group in the presence of Raney nickel provided $(R)$-baclofen $[(R)$ 1]. Similarly, Jørgensen and co-workers ${ }^{50}$ and Hayashi and co-workers ${ }^{51}$ employed ent-D as a catalyst in the synthesis of $(S)$-baclofen $[(S)-\mathbf{1}]$ via the asymmetric conjugate addition of nitromethane to aldehyde $\mathbf{7 4}$.
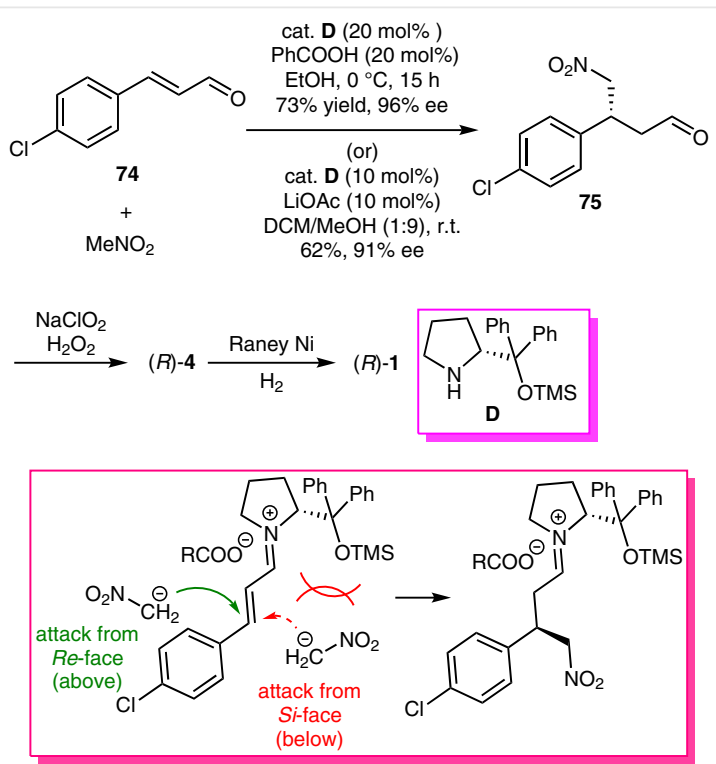

Scheme 27 Proline derivative catalyzed enantioselective Michael addition

In 2016, Šebesta and co-workers ${ }^{52 a}$ developed new chiral squaramide derivatives and employed them in the synthesis of GABAergic drugs using asymmetric Michael addition as the key step (Scheme 28). The asymmetric conjugate addition of nitromethane to aldehyde $\mathbf{7 4}$ in the presence of organocatalyst E (5 mol\%) provided 75 in $64 \%$ yield with $92 \%$ ee. The enantioselectivity is explained through the formation of an enamine transition state as shown in Scheme $28 .{ }^{52 a}$ Finally, compound $\mathbf{7 5}$ was converted into $(R)$-baclofen $[(R)-\mathbf{1}]$ in a three-step sequence: 1 . oxidation, 2 . reduction, and 3. acid hydrolysis.

Similarly, chiral squaramide $\mathbf{F}$ efficiently catalyzed enantioselective Michael addition of dimethyl malonate $(\mathbf{9})$ to 4-chloro- $\beta$-nitrostyrene (40) to provide $(R)$-baclofen precursor 76a in 76\% yield with $86 \%$ ee (Scheme 29). Pápai, Soós, and co-workers reported the mechanism of bifunctional squaramide-catalyzed Michael addition of 1,3-dicarbonyl compounds to nitrostyrene. ${ }^{52 \mathrm{~b}}$ In the transition state
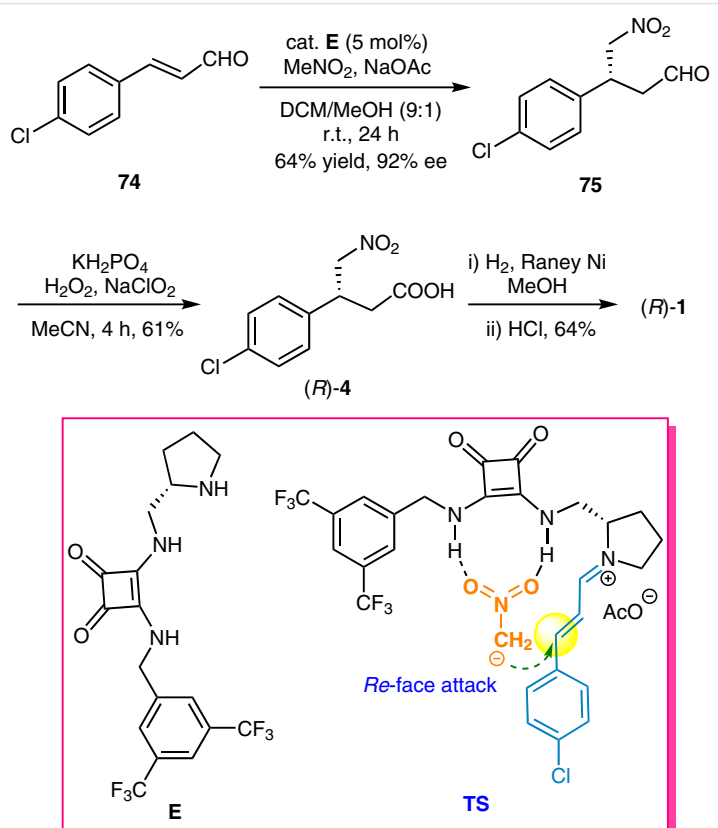

Scheme 28 Asymmetric Michael addition using squaramide organocatalyst

of carbon-carbon bond formation, carbonyl groups are bonded to both $\mathrm{NH}$ units of the catalyst as $\mathrm{N}-\mathrm{H}$-..O bonds (H-bonding). The $\mathrm{NO}_{2}$ group of the electrophile is bonded to the protonated amine, which stabilizes the negative charge developing on this unit upon carbon-carbon bond formation. Hydrogenation of optically pure nitro diester $\mathbf{7 6 a}$ in the presence of Raney nickel afforded pyrrolidinone derivative 77a, which was then subjected to ester hydrolysis followed by decarboxylation to give final product $(R)$-baclofen $[(R)-1]$ with $99 \%$ ee.

In 2009, Yasuoka and co-workers ${ }^{53}$ patented a route to $(R)$-baclofen $[(R)-\mathbf{1}]$ (Scheme 30). They utilized the method developed by Evans and Seidel ${ }^{54}$ to construct the chiral intermediate $\mathbf{7 6 b}$ of $(R)$-baclofen $[(R)-\mathbf{1}]$ via asymmetric Michael addition. 4-Chloro- $\beta$-nitrostyrene (40), prepared from the condensation of 4-chlorobenzaldehyde (10) with nitromethane, reacted with diethyl malonate in the presence of bis[(R,R)-N,N'-dibenzylcyclohexane-1,2-diamine]dibromonickel(II) catalyst $\mathbf{G}(2 \mathrm{~mol} \%)$ in toluene at $50{ }^{\circ} \mathrm{C}$ for seven hours, affording the Michael adduct $\mathbf{7 6 b}$ in $74 \%$ yield with $94 \%$ ee. The enol form of diethyl malonate coordinates to the nickel complex and nucleophilic attack on nitrostyrene could proceed through a transition structure in which the electrostatic and reinforcing steric effects might orient the nitrostyrene molecule. ${ }^{54}$ Therefore, the obtained addition product has $R$ configuration. The chiral intermediate 76b was transformed into $(R)$-baclofen $[(R)-\mathbf{1}]$ via a sequence similar to the one in Scheme 29. 


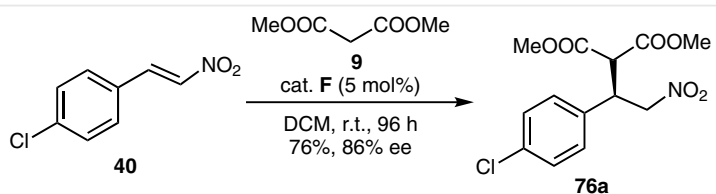

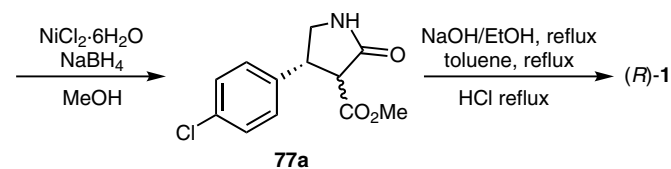

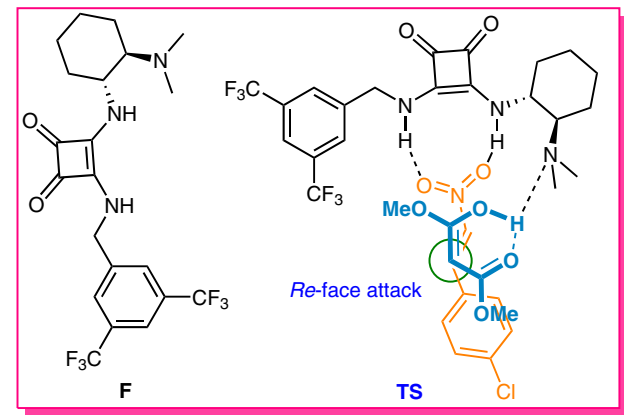

Scheme 29 Asymmetric Michael addition using squaramide organocatalyst

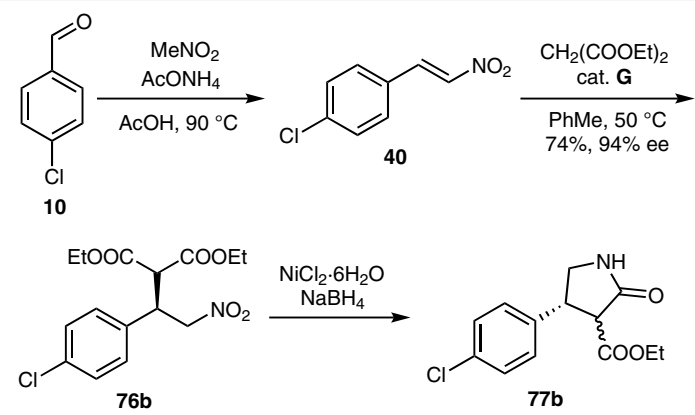

$$
\underset{\text { or } \mathrm{HCl} \text { reflux }}{\stackrel{\mathrm{NaOH} \text {, reflux }}{\mathrm{HCl}}}(R)-1
$$

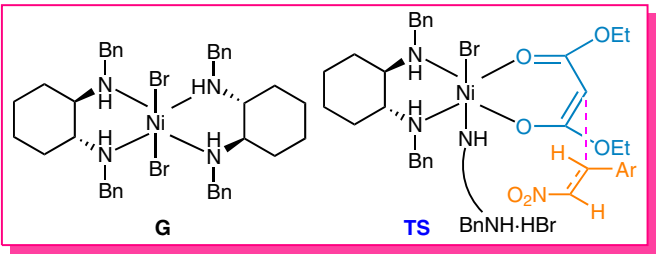

Scheme 30 Nickel-catalyzed Michael addition

In 2003, Takemoto and co-workers ${ }^{55}$ developed the first chiral bifunctional thiourea organocatalyst and applied it to the asymmetric Michael addition of malonates to nitroalkenes. In this chiral bifunctional thiourea organocatalyst, the thiourea moiety acts as the Brønsted acidic part and lowers the lowest unoccupied molecular orbital (LUMO) level of the electrophile. At the same time, the

amine group of the chiral scaffold acts as the Lewis basic part and raises the highest occupied molecular orbital (HOMO) level of the nucleophile (Figure 2). ${ }^{56,57}$

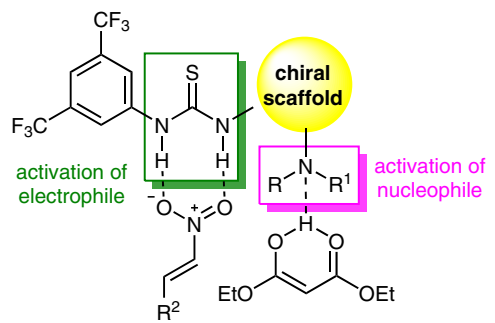

Figure 2 Amine-thiourea organocatalysts for dual activation of the substrates

Takemoto and co-workers reported the thiourea bifunctional organocatalyst $\mathbf{H}$ catalyzed enantioselective Michael addition of diethyl malonate to 4-chloro- $\beta$-nitrostyrene (40) to provide the Michael adduct $\mathbf{7 6 b}$ in $80 \%$ yield and $94 \%$ ee (Scheme 31). ${ }^{56}$ The acidic proton of diethyl malonate is deprotonated by the amino group of thiourea organocatalyst $\mathbf{H}$ and generates a nucleophile. Then nitrostyrene $\mathbf{4 0}$ interacts with the thiourea moiety through the formation of hydrogen bonding. Based on the product formation with $R$ configuration, the malonate nucleophile would attack nitrostyrene from the $R e$ face instead of the $S i$ face, which might be due to steric repulsions of the cyclohexyl scaffold

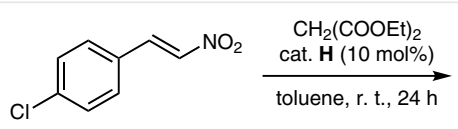

40

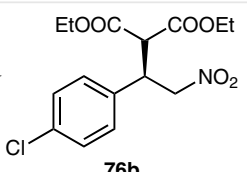

$>99 \%$ ee after single recrystallization from hexane/EtOAc
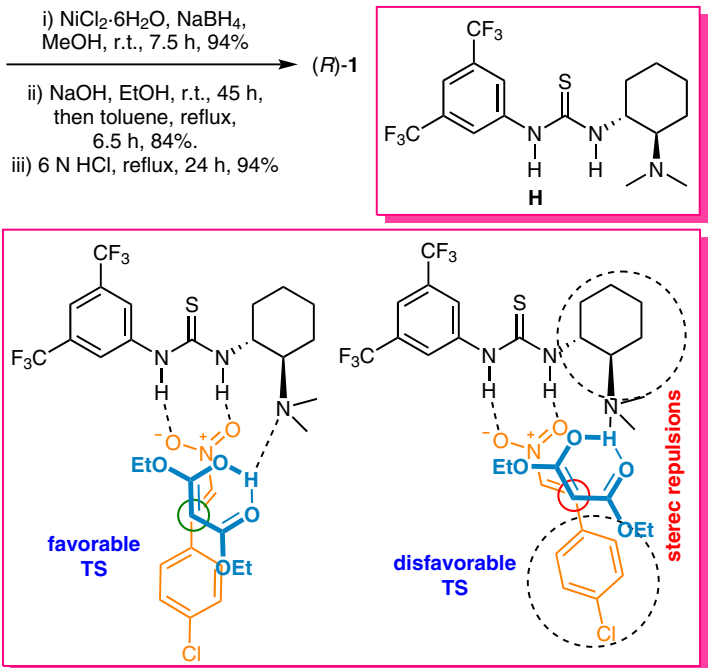

Scheme 31 Enantioselective Michael addition catalyzed by thiourea bifunctional organocatalyst 
with the phenyl ring of the nitrostyrene. The optically pure intermediate 76b was further converted into $(R)$-baclofen [(R)-1].

García-García, Corma, and Leyva-Pérez ${ }^{58}$ prepared multi-site organic-inorganic hybrid catalysts and employed them in the synthesis of GABAergic drugs. Condensation of aldehyde $\mathbf{1 0}$ with nitromethane followed by asymmetric Michael addition with dimethyl malonate (9) in a one-pot multicomponent transformation in the presence of ureamodified chiral cinchona alkaloid derivative I on a mesoporous siliceous material with additional pending aminopropyl groups afforded 76a in $77 \%$ yield with $70 \%$ ee (Scheme 32). Compound 76a was converted into the corresponding baclofen intermediate $(R)-\mathbf{8}$ by a one-pot procedure using palladium on carbon ( $2 \mathrm{~mol} \%, 20 \mathrm{mg}$ of $5 \mathrm{wt} \%$ solids) solid catalyst under hydrogen. Finally, the acid hydrolysis provided $(R)$-baclofen $[(R)-\mathbf{1}]$.
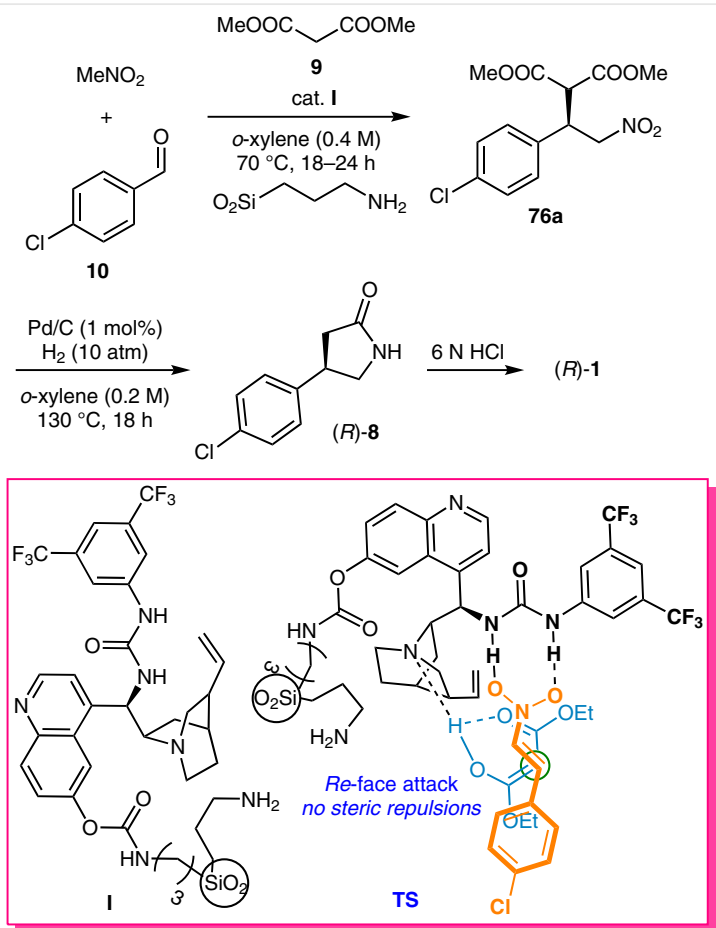

Scheme 32 Multicomponent reaction catalyzed by urea-modified chiral cinchona alkaloid solid catalyst

In 2011, Tian, Lin, and co-workers ${ }^{59}$ synthesized a new chiral cinchona alkaloid organocatalyst J, for the asymmetric conjugate addition of 1,3-dicarbonyl compounds to nitroalkenes. By employing the bifunctional biscinchona alkaloid $\mathbf{J}$ as the catalyst, the conjugate addition of compound $\mathbf{4 0}$ with dimethyl malonate $(\mathbf{9})$ proceeded well to afford the desired product $\mathbf{7 6 a}$ in $87 \%$ yield with $>99 \%$ ee (after recrystallization) (Scheme 33). A similar synthetic sequence to the one in Scheme 29 was used for the preparation of $(R)-\mathbf{1}$ from 76a.
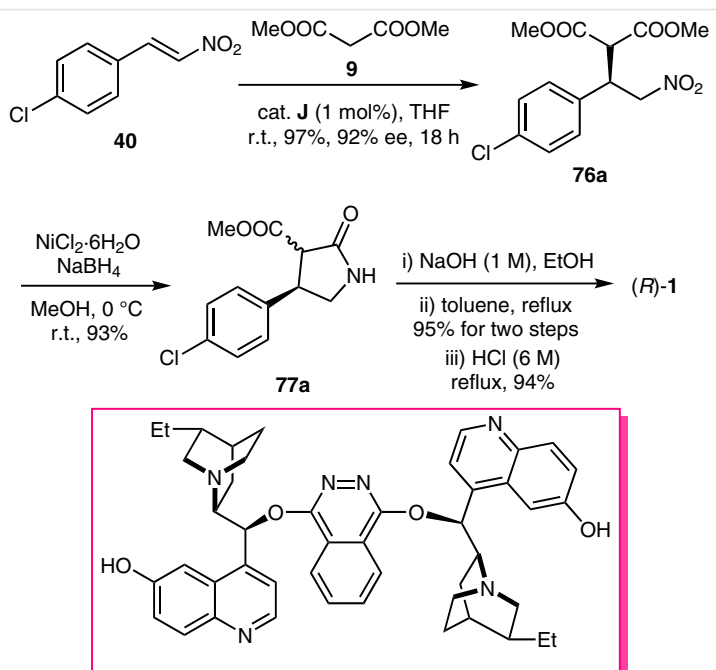

(deMeDHQD)2PHAL-J

Scheme 33 Asymmetric conjugate addition using biscinchona alkaloid organocatalyst

In 2013, Tsogoeva and co-workers ${ }^{60}$ reported the successful asymmetric Michael addition of nitroalkanes to various $\alpha, \beta$-unsaturated ketones catalyzed by primary aminethiourea catalyst $\mathbf{K}$, providing Michael adducts in good yields with excellent enantioselectivities. The enantioselective Michael addition of nitromethane to $(E)$-1-(4-chlorophenyl)-4-methylpent-1-en-3-one (78) provided the desired product 79 in $85 \%$ yield with $98 \%$ ee (Scheme 34 ). The
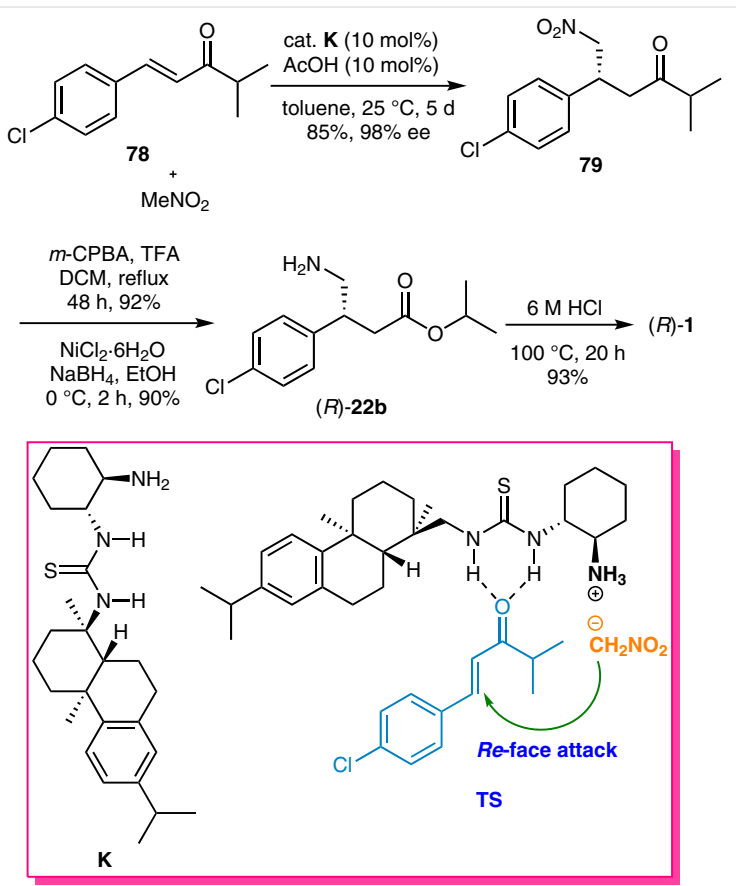

Scheme 34 Primary amine thiourea bifunctional organocatalyst catalyzed asymmetric Michael addition 
compound 78 is activated via hydrogen-bonding interactions between the thiourea two $\mathrm{NH}$ moieties of the catalyst and the carbonyl group of ketone 78. Furthermore, the $R \boldsymbol{e}$ face approach of nitromethane is induced by the amine group of the catalyst $\mathbf{K}$ and leads to the formation of product with $R$-configuration. Baeyer-Villiger oxidation followed by nitro group reduction yielded the amino ester $(R)$ 22b, which on acid hydrolysis provided the target molecule $(R)$-baclofen $[(R)-\mathbf{1}]$.

Corey and co-workers ${ }^{61}$ used chiral quaternary ammonium salt as a catalyst $\mathbf{L}$ in their asymmetric synthesis of $(R)$-baclofen $[(R)-1]$ (Scheme 35). The synthesis commenced with Michael addition of nitromethane to $\alpha, \beta$ enone $\mathbf{8 0}$ in the presence of cinchoninium salt $\mathbf{L}$ (10 mol\%) at $-40{ }^{\circ} \mathrm{C}$ in toluene to afford Michael adduct $\mathbf{8 1}$ in $89 \%$ yield with $70 \%$ ee. A single recrystallization from EtOAc/hexane mixture afforded enantiomerically pure $\mathbf{8 1}$ with 95\% ee. Baeyer-Villiger oxidation of ketone $\mathbf{8 1}$ in the presence of $\mathrm{m}$ CPBA in the next step afforded nitro ester $\mathbf{8 2}$ in $90 \%$ yield. Compound 82 was further converted into $(R)$-baclofen $[(R)$ 1] via reduction followed by acid hydrolysis of the corresponding pyrrolidone $(R)-\mathbf{8}$.

The catalytic asymmetric conjugate addition of nitromethane with $\alpha, \beta$-unsaturated thioamides was described by Kumagai, Shibasaki, and co-workers. ${ }^{62}$ With the mesityl-<smiles>COc1cc(/C=C/C(=O)c2ccccc2)ccc1Cl</smiles><smiles>O=C(C[C@H](C[N+](=O)[O-])c1ccc(Cl)cc1)Oc1ccccc1</smiles><smiles>O=C1C[C@@H](c2ccc(Cl)cc2)CN1</smiles>

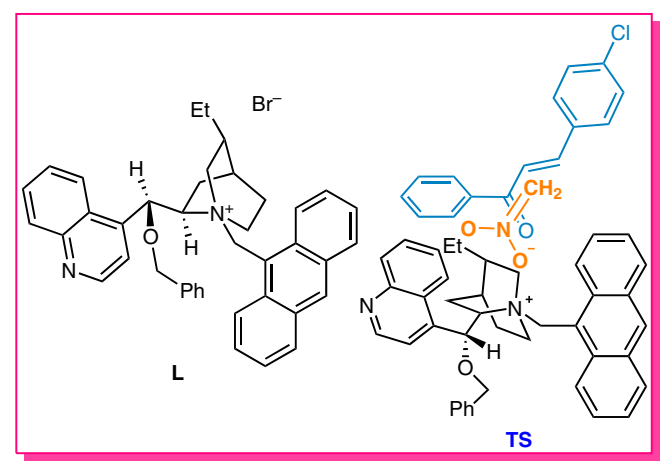

Scheme 35 Chiral quaternary ammonium salt catalyzed enantioselective Michael addition copper $/(R)$-DTBM-Segphos precatalyst, the asymmetric addition of nitromethane to $\mathbf{8 3}$ gave the desired product $\mathbf{8 4}$ in 92\% yield with high enantioselectivity, 99\% ee (Scheme 36 ). Thioester $\mathbf{8 5}$ was obtained by the reaction of thioamide $\mathbf{8 4}$ with MeI/TFA in wet THF. ${ }^{63}$ Finally, thioester 85 was converted into $(R)$-baclofen $[(R)-\mathbf{1}]$ by hydrolysis and reduction.
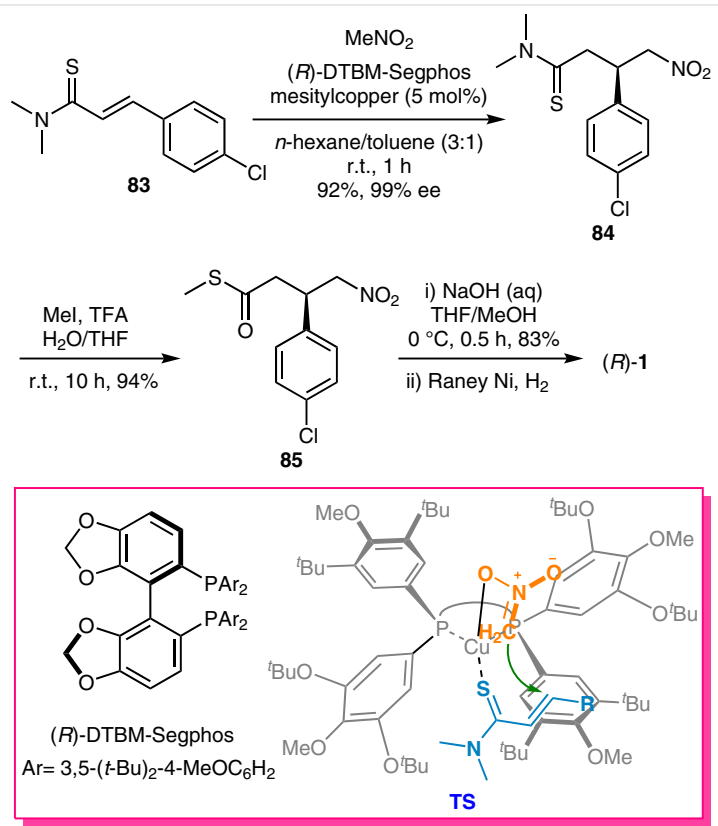

Scheme 36 Mesitylcopper/(R)-DTBM-Segphos catalyzed asymmetric conjugate addition

Helmchen and co-workers reported ${ }^{64}$ the asymmetric addition of arylboronic acids to $\mathrm{N}$-protected 4-aminobut-2enoic acid derivatives using a rhodium catalyst and chiral BINAP as a ligand. The starting material $\mathbf{8 7}$ was prepared from $N$-protected 2-aminoethanol 86 using IBX oxidation followed by Horner-Wadsworth-Emmons olefination. The Michael adduct $\mathbf{8 8}$ was obtained in quantitative yield with $89 \%$ ee by the enantioselective addition of 4-chlorophenylboronic acid (63) to unsaturated ester 87 in the presence of [Rh(acac) $\left.\left(\mathrm{C}_{2} \mathrm{H}_{4}\right)_{2}\right]$ (4.5 mol\%) catalyst and (S)-BINAP ligand in dioxane/water (10:1) (Scheme 37). The (S)-BINAP-rhodium intermediate should have an open space at the lower part of the vacant coordination site, the upper part is blocked by one of the phenyl rings of the (S)-BINAP ligand. ${ }^{65}$ Therefore, the unsaturated ester coordinates to rhodium with its $2 R e$ face rather than its $2 S i$ face. The 1,4addition of the aryl group to the unsaturated ester leads to the formation of product with $R$-absolute configuration. ${ }^{65 \mathrm{~b}}$ Deprotection of the Boc group followed by ester hydrolysis provided $(R)-\mathbf{1}$. 

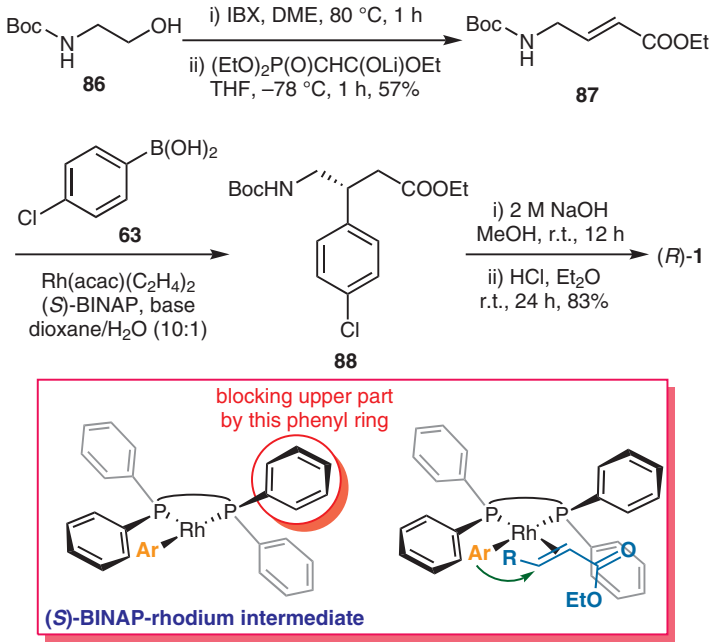

Scheme 37 Rhodium-catalyzed conjugate addition

A set of chiral dienes was screened by Feng, Lin, and coworkers ${ }^{66}$ for the asymmetric addition of arylboronic acids to $\alpha, \beta$-unsaturated $\gamma$-lactams in the presence of rhodium catalyst. The chiral diene $\mathbf{M}$ was found to be the best ligand. In the presence of rhodium/diene complex as a catalyst, the adduct $\mathbf{9 0}$ was obtained in 99\% yield with high enantioselectivity, $97 \%$ ee (Scheme 38). The rhodium complex of chiral ligand $\mathbf{M}$ recognizes the enantioface of the $\alpha, \beta$-unsaturated $\gamma$-lactam 89 by the steric repulsions between the phen$\mathrm{yl}$ group on the chiral ligand $\mathbf{M}$ and the carbonyl moiety of the unsaturated lactam, the coordination with the $\alpha$ Re face is favorable for the unsaturated lactam, which leads to the formation of product with $R$ configuration. ${ }^{67}$ After a single recrystallization, the enantiomeric excess of $\mathbf{9 0}$ increased to $>99 \%$. Deprotection of the Boc group, followed by hydrolysis completed the synthetic sequence to enantiomerically pure $(R)$-baclofen $[(R)-\mathbf{1}]$.
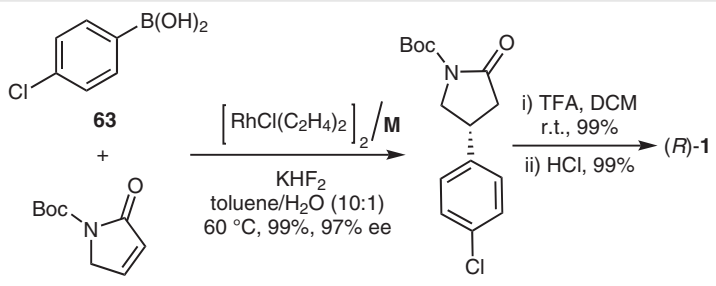$$
89
$$

90

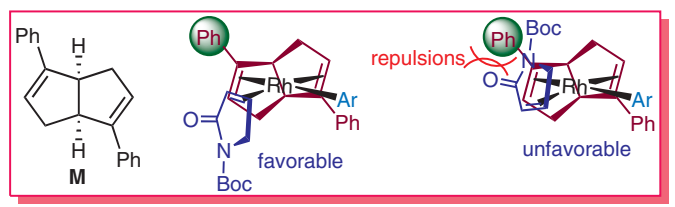

Scheme 38 Rhodium/diene-catalyzed 1,4-additions

\section{Conclusion}

In conclusion, baclofen is the only available selective agonist of the $G_{A B A}$ receptor and it is used as a muscle relaxant. It is also used in the treatment of the paroxysmal pain of trigeminal neuralgia. The pharmaceutical activity of baclofen resides in the $R$-enantiomer only. This review focused on the numerous asymmetric strategies used for the synthesis of the antispastic drug $(R)$-baclofen.

\section{Funding Information}

D.S. and K.S.N.R. thank the Council of Scientific and Industrial Research, New Delhi for financial assistance in the form of a fellowship. P. R. thanks the Council of Scientific and Industrial Research, Ministry of Science and Technology, New Delhi, for funding the project ORIGIN (CSC-0108).

\section{References}

(1) (a) Froestl, W. Adv. Pharmacol. 2010, 58, 19. (b) Yogeeswari, P.; Ragavendran, J. V.; Sriram, D. Recent Pat. CNS Drug Discovery 2006, 1, 113.

(2) (a) Bowery, N. G.; Hill, D. R.; Hudson, A. L.; Doble, A.; Middemiss, N. D.; Shaw, J.; Turnbull, M. Nature (London) 1980, 283, 92. (b) Silverman, R. B.; Levy, M. A. J. Biol. Chem. 1981, 256, 11565. (c) Mann, A.; Boulanger, T.; Brandau, B.; Durant, F.; Evrard, G.; Haeulme, M.; Desaulles, E.; Wermuth, C. G. J. Med. Chem. 1991, 34, 1307.

(3) (a) Pierau, F. K.; Zimmerman, P. Brain Res. 1973, 54, 376. (b) Polc, P.; Haefely, W. Naunyn-Schmiedberg's Arch. Pharmacol. 1976, 294, 121.

(4) Goka, V. N.; Schlewer, G.; Linget, J. M.; Chambon, J. P.; Wermuth, C. G.J. Med. Chem. 1991, 34, 2547.

(5) Fromm, G. H.; Terrence, C. F.; Chaftha, H. S.; Glass, J. D. Arch. Neural. 1980, 37, 768.

(6) Hudgson, P.; Weightman, D. Br. Med.J. 1971, 4, 15.

(7) Olpe, H. R.; Demiéville, H.; Baltzer, V.; Benzce, W. L.; Koella, W. P.; Wolf, P.; Haas, H. L. Eur. J. Pharmacol. 1978, 52, 133.

(8) Chang, C.-H.; Yang, D. S. C.; Yoo, C. S.; Wang, B.-C.; Pletcher, J.; Sax, M.; Terrence, C. F. Acta Crystallogr., Sect. B 1982, 38, 2065.

(9) Caira, M. R.; Clauss, R.; Nassimbeni, L. R.; Scott, J. L.; Wildervanck, A. F. J. Chem. Soc., Perkin Trans. 2 1997, 763.

(10) Camps, P.; Muñoz-Torrero, D.; Sánchez, L. Tetrahedron: Asymmetry 2004, 15, 2039.

(11) Montoya-Balbas, I. J.; Valentin-Guevara, B.; Lopez-Mendoza, E.; Linzaga-Elizalde, I.; Ordonez, M.; Roman-Bravo, P. Molecules 2015, 20, 22028.

(12) (a) Brenna, E.; Fuganti, C.; Gatti, F. G.; Serra, S. Chem. Rev. 2011, 111, 4036. (b) Nestl, B. M.; Nebel, B. A.; Hauer, B. Curr. Opin. Chem. Biol. 2011, 15, 187. (c) Ramesh, P.; Harini, T.; Fadnavis, N. W. Org. Process Res. Dev. 2015, 19, 296. (d) Ramesh, P.; Anjibabu, R.; Reddy, Y. N.; Yedukondalu, M.; Reddy, T. N.; Kummari, B.; Raju, A.; Srinivasu, N. Asian J. Org. Chem. 2017, 6, 984. (e) McCubbin, J. A.; Maddess, M. L.; Lautens, M. Synlett 2008, 289.

(13) Wang, M.-X.; Zhao, S.-M. Tetrahedron Lett. 2002, 43, 6617.

(14) Felluga, F.; Gombac, V.; Pitacco, G.; Valentin, E. Tetrahedron: Asymmetry 2005, 16, 1341. 
(15) Veinberg, G.; Vorona, M.; Lebedevs, A.; Chernobrovijs, A.; Kalvinsh, I. WO2007096314, 2007.

(16) (a) Rachwalsk, M.; Vermue, N.; Rutjes, F. P. J. T. Chem. Soc. Rev. 2013, 42, 9268. (b) Garcia-Urdiales, E.; Alfonso, I.; Gotor, V. Chem. Rev. 2011, 111, 110.

(17) (a) Chen, Y.; Tian, S.-K.; Deng, L. J. Am. Chem. Soc. 2000, 122, 9542. (b) Chen, Y.; Deng, L. J. Am. Chem. Soc. 2001, 123, 11302.

(18) Ji, L.; Ma, Y.; Li, J.; Zhang, L.; Zhang, L. Tetrahedron Lett. 2009, 50, 6166.

(19) (a) Corey, E. J.; Noe, M. C. J. Am. Chem. Soc. 1996, 118, 319. (b) Harding, M.; Bodkin, J. A.; Issa, F.; Hutton, C. A.; Willis, A. C.; McLeod, M. D. Tetrahedron 2009, 65, 831. (c) Corey, E. J.; Guzman-Perez, A.; Noe, M. C. Tetrahedron Lett. 1995, 36, 3481.

(20) Yan, L.-J.; Wang, H.-F.; Chen, W.-X.; Tao, Y.; Jin, K.-J.; Chen, F.-E. ChemCatChem 2016, 8, 2249.

(21) Wang, S.-X.; Chen, F.-E. Adv. Synth. Catal. 2009, 351, 547.

(22) Chenevert, R.; Desjardins, M. Can. J. Chem. 1994, 72, 2312.

(23) Mazzini, C.; Lebreton, J.; Alphand, V.; Furstoss, R. Tetrahedron Lett. 1997, 38, 1195.

(24) Kaiwar, V.; Reese, C. B.; Gray, E. J.; Neidle, S. Z. J. Chem. Soc., Perkin Trans. 1 1995, 2281.

(25) (a) Wang, M.-X.; Liu, C.-S.; Li, J.-S.; Meth-Cohn, O. Tetrahedron Lett. 2000, 41, 8549. (b) Wang, M.-X.; Liu, C.-S.; Li, J.-S. Tetrahedron: Asymmetry 2001, 12, 3367.

(26) Duan, Y.; Yao, P.; Ren, J.; Han, C.; Li, Q.; Yuan, J.; Feng, J.; Wu, Q.; Zhu, D. Sci. China: Chem. 2014, 57, 1164.

(27) (a) Licandro, E.; Maiorana, S.; Baldoli, C.; Capella, L.; Perdicchia, D. Tetrahedron: Asymmetry 2000, 11, 975. (b) Licandro, E.; Maiorana, S.; Capella, L.; Manzotti, R.; Papagni, A.; Vandoni, B.; Albinati, A.; Chuang, S. H.; Hwu, J.-R. Organometallics 2001, 20, 485.

(28) Kuo, J.-H.; Wong, W.-C. US 20120029230, 2012.

(29) Oba, M.; Saegusa, T.; Nishiyama, N.; Nishiyama, K. Tetrahedron 2009, 65, 128

(30) Chang, M.-Y.; Sun, P.-P.; Chen, S.-T.; Chang, N.-C. Tetrahedron Lett. 2003, 44, 5271.

(31) Chang, M.-Y.; Chen, C.-Y.; Tasi, M.-R.; Tseng, T.-W.; Chang, N.-C. Synthesis 2004, 840.

(32) Khatik, G. L.; Khurana, R.; Kumar, V.; Nair, V. A. Synthesis 2011, 3123.

(33) Schoenfelder, A.; Mann, A.; Le Coz, S. Synlett 1993, 63.

(34) Evans, D. A.; Ennis, M. D.; Mathre, D. J. J. Am. Chem. Soc. 1982, $104,1737$.

(35) Enders, D.; Niemeier, O. Heterocycles 2005, 66, 385.

(36) Job, A.; Janeck, C. F.; Bettray, W.; Peters, R.; Enders, D. Tetrahedron 2002, 58, 2253; and references therein.

(37) Bauer, W.; Seebach, D. Helv. Chim. Acta 1984, 67, 1972.

(38) Thakur, V. V.; Nikalje, M. D.; Sudalai, A. Tetrahedron: Asymmetry 2003, 14, 581

(39) Noyori, R.; Sandoval, C. A.; Muniz, K.; Ohkuma, T. Philos. Trans. R. Soc., A 2005, 363, 901.

(40) Paraskar, A. S.; Sudalai, A. Tetrahedron 2006, 62, 4907.
(41) Leutenegger, M. A.; Pfaliz, A. Angew. Chem., Int. Ed. Engl. 1989, 28,60 .

(42) Deng, J.; Duan, Z.-C.; Huang, J.-D.; Hu, X.-P.; Wang, D.-Y.; Yu, S.B.; Xu, X.-F.; Zheng, Z. Org. Lett. 2007, 9, 4825.

(43) Deng, J.; Hu, X.-P.; Huang, J.-D.; Yu, S.-B.; Wang, D.-Y.; Duan, Z.C.; Zheng, Z. J. Org. Chem. 2008, 73, 6022.

(44) Mita, T.; Higuchi, Y.; Sato, Y. Chem. Eur. J. 2015, 21, 16391.

(45) Brenna, E.; Crotti, M.; Gatti, F. G.; Monti, D.; Parmeggiani, F.; Powell, R. W. III.; Santangelo, S.; Stewart, J. D. Adv. Synth. Catal. 2015, 357, 1849.

(46) Dean, W. D.; Blum, D. M. J. Org. Chem. 1993, 58, 7916.

(47) Fryszkowska, A.; Fisher, K.; Gardiner, J. M.; Stephens, G. M. Org. Biomol. Chem. 2010, 8, 533.

(48) Zu, L.; Xie, H.; Li, H.; Wang, J.; Wang, W. Adv. Synth. Catal. 2007, 349, 2660.

(49) (a) Wang, Y.; Li, P.; Liang, X.; Zhang, T. Y.; Ye, J. Chem. Commun. 2008, 1232. (b) Mukherjee, S.; Yang, J. W.; Hoffmann, S.; List, B. Chem. Rev. 2007, 107, 5471. (c) Marigo, M.; Bertelsen, S.; Landa, A.; Jorgensen, K. A. J. Am. Chem. Soc. 2006, 128, 5475.

(50) Jensen, K. L.; Poulsen, P. H.; Donslund, B. S.; Morana, F.; Jørgensen, K. A. Org. Lett. 2012, 14, 1516.

(51) Hayashi, Y.; Sakamoto, D.; Okamura, D. Org. Lett. 2016, 18, 4.

(52) (a) Veverková, E.; Bilka, S.; Baran, R.; Šebesta, R. Synthesis 2016, 48, 1474. (b) Kótai, B.; Kardos, G.; Hamza, A.; Farkas, V.; Pápai, I.; Soós, T. Chem. Eur. J. 2014, 20, 5631.

(53) Yasuoka, J.; Fukuyo, S.; Ikemoto, T. US 2009/0137819, 2009.

(54) Evans, D. A.; Seidel, D. J. Am. Chem. Soc. 2005, 127, 9958.

(55) Okino, T.; Hoashi, Y.; Takemoto, Y. J. Am. Chem. Soc. 2003, 125, 12672.

(56) Okino, T.; Hoashi, Y.; Furukawa, T.; Takemoto, Y. J. Am. Chem. Soc. 2005, 127, 119.

(57) Ojima, I. Catalytic Asymmetric Synthesis, 3rd ed.; Wiley-VCH: New York, 2010.

(58) Leyva-Pérez, A.; García-García, P.; Corma, A. Angew. Chem. Int. Ed. 2014, 53, 8687.

(59) Li, F.; Li, Y.-Z.; Jia, Z.-S.; Xu, M.-H.; Tian, P.; Lin, G.-Q. Tetrahedron 2011, 67, 10186.

(60) Serdyuk, O. V.; Heckel, C. M.; Tsogoeva, S. B. Org. Biomol. Chem. 2013, 11, 7051.

(61) Corey, E. J.; Zhang, F. Y. Org. Lett. 2000, 2, 4257.

(62) Ogawa, T.; Mouri, S.; Yazaki, R.; Kumagai, N.; Shibasaki, M. Org. Lett. 2012, 14, 110.

(63) Harrowven, D. C.; Lucas, M. C.; Howes, P. D. Tetrahedron 1999 $55,1187$.

(64) Becht, J.-M.; Meyer, O.; Helmchen, G. Synthesis 2003, 2805.

(65) (a) Ozawa, F.; Kubo, A.; Matsumoto, Y.; Hayashi, T. Organometallics 1993, 12, 4188; and references therein. (b) Takaya, Y.; Ogasawara, M.; Hayashi, T. J. Am. Chem. Soc. 1998, 120, 5579.

(66) Shao, C.; Yu, H.-J.; Wu, N.-Y.; Tian, P.; Wang, R.; Feng, C.-G.; Lin, G.-Q. Org. Lett. 2011, 13, 788.

(67) Hayashi, T.; Ueyama, K.; Tokunaga, N.; Yoshida, K. J. Am. Chem. Soc. 2003, 125, 11508. 